\title{
Novel insights into phenotype and mitochondrial proteome of yeast mutants lacking proteins Sco1p or Sco2p
}

\author{
Tania Gamberi ${ }^{\mathrm{a}}$, Francesca Magherini ${ }^{\mathrm{a}}$, Marina Borro ${ }^{\mathrm{b}}$, Giovanna Gentile ${ }^{\mathrm{b}}$, Duccio Cavalieri ${ }^{\mathrm{c}}$, \\ Emmanuela Marchi ${ }^{\mathrm{a}}$, Alessandra Modesti ${ }^{\mathrm{a}, *}$ \\ a Dipartimento di Scienze Biochimiche, Università degli Studi di Firenze, Viale G. Morgagni, 50, I-50134 Firenze, Italy \\ ${ }^{\mathrm{b}}$ Dipartimento di Scienze Biochimiche, II Facoltà di Medicina, Azienda Ospedaliera Sant'Andrea, Università La Sapienza Roma, Italy \\ ${ }^{\mathrm{c}}$ Dipartimento di Farmacologia, Università degli Studi di Firenze, Italy
}

\section{A R T I C L E I N F O}

Article history:

Received 3 October 2008

Received in revised form 6 December 2008

Accepted 5 January 2009

Available online 17 January 2009

\section{Keywords:}

Saccharomyces cerevisiae

Ethanol fermentation

Mitocondrial proteome

Respiratory chain

Respiratory-deficient yeast strain

\begin{abstract}
A B S T R A C T
The yeast Saccharomyces cerevisiae is a facultative anaerobe and its mitochondrial morphology is linked to its metabolic activity. The Sco proteins ( $\mathrm{Sco} 1 \mathrm{p}$ and $\mathrm{Sco} 2 \mathrm{p}$ ) were characterized as proteins required for copper delivery to cytochrome $c$ oxidase. Our results indicated a higher fermentative capacity of the sco1- $\Delta$ mutant in comparison to the control and the sco2- $\Delta$ mutant strains. The mitochondrial proteome analysis showed that the sco1- $\Delta$ mutant down-regulated components of the respiratory chain, the TCA cycle and transport of metabolites across the mitochondrial membrane. This evidence suggests that the absence of Sco1p causes irreversible damage to the mitochondria.
\end{abstract}

(c) 2009 Elsevier B.V. and Mitochondria Research Society. All rights reserved.

\section{Introduction}

The yeast Saccharomyces cerevisiae is a facultative anaerobe able to live on various carbon sources including fermentable and nonfermentable substances. The fact that respiration is not essential for viability makes this organism ideal for the biochemical study of the processes responsible for the function of mitochondria. Respiration induced by a non-fermentable carbon source or by caloric restriction, seems to induce a good mitochondrial metabolic activity with low ROS leakage from the respiratory chain. Many authors report that a restricted dietary intake increases the rate of oxygen consumption thus indicating an increase in mitochondrial respiration (Lin et al., 2002; Smith et al., 2007). We previously reported that exposure of yeast cells to oxidative stress provokes a decrease in peroxiredoxin II and GST I expression. This induces a perturbation that leads to apoptosis (Magherini et al., 2007). The reduction the concentration of glucose in the medium results in an increase

Abbreviations: 2D, two-dimensional; CHAPS, 3-(3-cholamidopropyl)diethylammonio-1-propanesulfonate; EDTA, ethylenediaminetetraacetic acid; MALDI, matrix-assisted laser desorption/ionization; MOPS, 3-( $N$-morpholino) propanesulfonic acid; MS, mass spectrometry; MS/MS, tandem mass spectrometry; OD, optical density; PAGE, polyacrylamide gel electrophoresis; $\mathrm{pI}$, isoelectric point; SDS, sodium dodecyl sulfate; SGD, Saccharomyces genome database.

* Corresponding author. Tel.: +39 055459 8311; fax: +39 0554598905.

E-mail address: modesti@scibio.unifi.it (A. Modesti). of life span. This is probably due to an increase in respiratory activity and to the activation of a signal pathway, known as retrograde response, from the mitochondria to the nucleus (Jiang et al., 2000; Butow and Avadhani, 2004). This retrograde response indicates mitochondrial dysfunction. Visser et al. (1995) conducted a detailed investigation of mitochondria morphology in S. cerevisiae that shows that reticular morphology is associated to a repressed condition typical of growth on high glucose media or in oxygen absence whereas yeast cells growing on non-fermentable carbon sources display a large number of small mitochondria. Therefore mitochondrial morphology in S. cerevisiae is closely linked to the metabolic activity of the yeast. This situation is not reproducible in mammalian cells. The isolation and characterization of mitochondrial mutants has provided fundamental information on the biogenesis and function of mitochondria. Deficiencies in cytochrome $c$ oxidase (COX), the terminal enzyme of the mitochondrial respiratory chain, are the most frequent causes of respiratory defects in human. These deficiencies are often due to an inability to complete assembly of the enzyme. Specific proteins are implicated in the assembly of each of the four redox active centres of (COX) (Palmer, 1993). Two of these assembly factors are the Sco proteins which were first characterized in yeast as proteins necessary for accumulation of the cytochrome $c$ oxidase subunits I and II (COXI and COXII) (Schulze and Rodel, 1989) and later proposed as participating in copper delivery to COX (Dickinson et al., 2000). SCO1 is a 
nuclear gene that codes for a constituent of the yeast's mitochondrial inner membrane and is essential for the expression of cytochrome $c$ oxidase. Mutations in SCO1 induce a deficiency specific to COX assembly but do not substantially affect other enzymes of the respiratory chain or of the ATPase. Sco1 deletion mutants (sco1- $\Delta$ ) exhibited growth defect compared to the control strain on respiratory carbon sources such as glycerol and ethanol. The paralog gene SCO2 shows an identity to SCO1 of approximately $50 \%$ and Sco2p shares a number of common features with Sco1p (Lode et al., 2002). The role of Sco2p in yeast is enigmatic as the deletion of $\mathrm{SCO} 2$ does not result in a respiratory-deficient phenotype. On the contrary, the human counterparts of these proteins are both essential for mitochondrial function (Glerum et al., 1996). In this study we evaluated the efficiency of fermentation in aerobic conditions for the two deletion mutants SCO1 and $\mathrm{SCO} 2$. The results indicate that the yeast strain lacking the protein Sco1p has, compared to the wild type and the sco2- $\Delta$ strains, a higher rate ethanol fermentation. We compared the mitochondrial proteome isolated from sco1- $\Delta$ and $s c 02-\Delta$ mutants. Proteomic comparisons provided a deep insight into the different quantities of specific mitochondrial proteins.

\section{Material and methods}

\subsection{Strains and media}

The strains used in the study are listed in Table 1 . The plasmid pYX142-mtGFP, ARS/CEN-LEU2, that allows a constitutive expression of mitochondria-targeted GFP, was used to obtain strains BY-mtGFP, sco1- $\Delta$ mtGFP and sco2- $\Delta$ mtGFP. Cells were grown at $30{ }^{\circ} \mathrm{C}$ in synthetic complete (SC) medium containing $0.67 \% \mathrm{w} / \mathrm{v}$ of Yeast Nitrogen Base without Amino Acids (USbiological) supplemented with complete Amino Acid dropout solution (USbiological). Carbon sources were either $2 \% \mathrm{w} / \mathrm{v}$ glucose, $0.5 \% \mathrm{w} / \mathrm{v}$ glucose, $20 \% \mathrm{w} / \mathrm{v}$ glucose, $2 \%$ galactose, $2 \% \mathrm{v} / \mathrm{v}$ ethanol, $3 \% \mathrm{v} / \mathrm{v}$ glycerol or molasses (from Eridania, Zuccherifici Nazionali S.p.A.). The viability of cells was tested on solid complete YPD medium (1\% $\mathrm{w} / \mathrm{v}$ yeast extract, $2 \% \mathrm{w} / \mathrm{v}$ peptone, $2 \% \mathrm{w} / \mathrm{v}$ glucose and $2 \% \mathrm{w} / \mathrm{v}$ agar) (USbiological). Yeast strains transformed with pYX142mtGFP were grown in SC medium containing $0.67 \% \mathrm{w} / \mathrm{v}$ of Yeast Nitrogen Base without Amino Acid but supplemented with Amino Acids dropout solution minus leucine (USbiological) .

\subsection{Growth phenotypes and fitness}

Yeast cells were picked from fresh colonies and grown at $30^{\circ} \mathrm{C}$, to an optical density (600 $\mathrm{nm}$ ) of $1-2$, in SC medium containing $2 \%$ glucose as carbon source. Cells were collected by centrifugation, washed with sterile water and then diluted to $10^{6}$ cells $/ \mathrm{ml}$ in SC fresh media supplemented with $2 \%$ glucose, $2 \%$ galactose, $0.5 \%$ glucose, $3 \%$ glycerol or $2 \%$ ethanol as carbon sources, using flasks with volume/medium ratio of $3: 1$. The growth rate was monitored by measuring the turbidity of the culture at $600 \mathrm{~nm}\left(\mathrm{OD}_{600}\right)$ on a spectrophotometer until it reached stationary phase ( $36 \mathrm{~h}$ ).
We examined the fitness of the yeast cells in terms of chronological aging. To determine the number of viable cells, serial dilution of aging cells were plated on YPD plates. The percentage of colony-forming units (c.f.u.) was obtained by relating the c.f.u. counts of cells during chronological aging to those at the beginning of stationary phase which were considered to be $100 \%$. Viability was defined as the ability of a single cell to form a colony within 2 days. One millilitre of this yeast growth was used to evaluate cell viability also by FUN-1 staining (Millard et al., 1997).

\subsection{Ethanol determination}

For ethanol determination, cells were grown in SC medium containing a fermentable carbon source such as $2 \%$ glucose or $2 \%$ galactose to an optical density $(600 \mathrm{~nm})$ of $1-2$, collected by centrifugation, washed and then diluted in their respective fresh media to $10^{6}$ cells $/ \mathrm{ml}$ using flasks with volume/medium ratio of $3: 1$. The ethanol amount was evaluated also on $20 \%$ glucose and on sugar molasses. In this case cells were grown in SC medium containing $2 \%$ glucose to an optical density $(600 \mathrm{~nm})$ of $1-2$, collected by centrifugation, washed and then diluted to $10^{6}$ cells $/ \mathrm{ml}$ in SC medium containing $20 \%$ glucose or molasses as fermentable carbon sources. The molasses contained about $50 \%$ of fermentable sugar ( $700 \mathrm{~g}$ of molasses diluted in $1400 \mathrm{~g}$ of sterile water, $\mathrm{pH}$ 5-5.2 with $\mathrm{HCl}$ ). One millilitre of the growth was harvested at exponential phase and after $24 \mathrm{~h}$ and then centrifuged. The cleared supernatant was collected to estimate the ethanol production. Ethanol was determined using alcohol-dehydrogenase/ aldehyde-dehydrogenase method (EnzyPlus, Diffchamb).

\subsection{Staining of cells with rhodamine B and fluorescence microscopy}

To evaluate the mitochondrial membrane potential, the isogenic, the sco1- $\Delta$ and the sco2- $\Delta$ mutant strains were grown in SC medium containing $2 \%$ glucose as carbon source, to an optical density $(600 \mathrm{~nm})$ of $1-2$, harvested by centrifugation, washed and resuspended to an optical density of 0.1 in SC medium containing $2 \%(\mathrm{w} / \mathrm{v})$ glucose or $3 \%(\mathrm{v} / \mathrm{v})$ glycerol. After $24 \mathrm{~h} 1$ OD of cells was collected by centrifugation, washed twice with sterile water and suspended in $500 \mu \mathrm{l}$ of staining solution ( $25 \mathrm{mM}$ glucose in $10 \mathrm{mM}$ Na-Hepes pH 7.2). Cells were treated with rhodamine hexyl ester (rhodamine B) (Molecular Probes) at a concentration of $50 \mathrm{nM}$ for $10-15 \mathrm{~min}$. The treated cells were washed twice with cold water and stored briefly in ice before microscopic examination on Leica TCF SP5 confocal microscope. Cell morphology was viewed by differential interface contrast, while the stained cells were analyzed using a green fluorescent filter.

\subsection{Mitochondria morphology}

The morphology of mitochondria was visualized in the control, the sco1- $\Delta$ and the sco2- $\Delta$ mutant strains using the plasmid pYX142-mtGFP (Westermann and Neupert, 2000) that allows a constitutive expression of mitochondria-targeted GFP. The cells were grown in SC medium minus leucine supplemented with $2 \%$

Table 1

Yeast strains used.

\begin{tabular}{|c|c|c|}
\hline Strain & Genotype & Source or reference \\
\hline BY4741 & MATa; his $3 \Delta 1 ;$ leu $2 \Delta 0 ;$ met $15 \Delta 0 ;$ ura $3 \Delta 0$ & Euroscarf \\
\hline BY4741 sco1- $\Delta$ & Mat a; his $3 \Delta 1$; leu2 $\Delta 0 ;$ met15 $\Delta 0$; ura3 $\Delta 0 ;$ YBR037c::kanMX4 & Euroscarf \\
\hline BY4741 sco2- $\Delta$ & Mat a; his $3 \Delta 1$; leu2 $\Delta 0$; met $15 \Delta 0$; ura3 $\Delta 0$; YBR024w::kanMX4 & Euroscarf \\
\hline BY-mitoGFP & BY4741 + pYX142-mitoGFP, ARS/CEN-LEU2 & This study \\
\hline sco1- $\Delta$ mitoGFP & sco1- $\Delta+$ pYX142-mitoGFP, ARS/CEN-LEU2 & This study \\
\hline sco2- $\Delta$ mitoGFP & sco2- $\Delta+$ pYX142-mitoGFP, ARS/CEN-LEU2 & This study \\
\hline
\end{tabular}


glucose to an optical density (600 nm) of 1-2, harvested by centrifugation, washed, and resuspended to an optical density of 0.1 in SC medium minus leucine containing $2 \%(\mathrm{w} / \mathrm{v})$ glucose or $3 \%$ (v/v) glycerol. After $24 \mathrm{~h} 1 \mathrm{OD}$ of cells was collected by centrifugation, washed twice in $10 \mathrm{mM}$ Hepes buffer, immobilized with $0.5 \%$ Low Melting Point Agarose (Sigma) and visualized on Leica TCF SP5 confocal microscope.

\subsection{Preparation of mitochondria}

S. cerevisiae strains grown in SC medium with $2 \%$ glucose to an optical density ( $600 \mathrm{~nm}$ ) of 1-2 were collected by centrifugation, washed, and resuspended to an optical density of 0.1 in SC medium containing 3\% (v/v) glycerol instead of D-glucose. After $24 \mathrm{~h}$ cells were collected and mitochondria were purified essentially as described by Meisinger et al. (2000) with minor modifications. Cells were pelleted by centrifugation at $3000 \mathrm{~g}$ for $10 \mathrm{~min}$, washed twice with distilled water, suspended at $5 \times 10^{9} / \mathrm{ml}$ in DTT buffer (100 mM Tris-SO ${ }_{4} \mathrm{pH} 9.4,10 \mathrm{mM}$ dithiothreitol) and shaken for $10 \mathrm{~min}$ at $30^{\circ} \mathrm{C}$. The cells were then washed once with $1.2 \mathrm{M}$ sorbitol and resuspended in zymolyase buffer (1.2 M sorbitol, $20 \mathrm{mM} \mathrm{KPO}_{4} \mathrm{pH} 7.4$ ) at $1.5 \times 10^{9} / \mathrm{ml}$. Zymolyase-20T (USbiological) was added to a final concentration of $0.1 \mathrm{mg} / \mathrm{ml}$ and the suspension was incubated for $30 \mathrm{~min}$ at $30^{\circ} \mathrm{C}$ with gentle swirling for conversion into spheroplasts. The spheroplasts were harvested by centrifugation at room temperature and washed twice with $1.2 \mathrm{M}$ sorbitol. They were then suspended in ice-cold homogenization buffer $(0.6 \mathrm{M}$ mannitol, $10 \mathrm{mM}$ Tris- $\mathrm{HCl}$ ph $7.4,1 \mathrm{mM} \mathrm{PMSF}$ ) to a concentration of $0.15 \mathrm{~g}$ spheroplasts (wt weight) $/ \mathrm{ml}$. Homogenization was carried out by 15 strokes in a glass-Teflon potter. The homogenate was then diluted with $1 \mathrm{vol}$ of the homogenization buffer and centrifuged at $1500 \mathrm{~g}$ for $5 \mathrm{~min}\left(4^{\circ} \mathrm{C}\right)$ to remove cell debris and nuclei. The supernatant was centrifuged at $12,000 \mathrm{~g}$ for $15 \mathrm{~min}\left(4^{\circ} \mathrm{C}\right)$. The mitochondrial pellet was washed with SEM buffer (250 mM sucrose, $1 \mathrm{mM}$ EDTA, $10 \mathrm{mM}$ Mops, pH 7.2) and again pelleted at $12,000 \mathrm{~g}$ for $15 \mathrm{~min}$. Resulting crude mitochondrial fraction was suspended in SEM buffer to a final concentration of $5 \mathrm{mg} / \mathrm{ml}$, treated by 10 strokes in a glass-Teflon potter and loaded onto three-step sucrose gradient $[1.5 \mathrm{ml} 60 \%, 4 \mathrm{ml} 32 \%$, $1.5 \mathrm{ml} 23 \% .1 .5 \mathrm{ml} \mathrm{15 \% (w/v)} \mathrm{sucrose} \mathrm{in} \mathrm{EM} \mathrm{buffer} \mathrm{(10} \mathrm{mM} \mathrm{Mops}$ $\mathrm{pH} 7.2,1 \mathrm{mM}$ EDTA)]. After centrifugation at $134,000 \mathrm{~g}$ in a Beckman SW41 swinging-bucket rotor for $1 \mathrm{~h}$ at $4{ }^{\circ} \mathrm{C}$, the purified mitochondria were recovered from the $60 \%$ to $32 \%$ interface. They were then diluted with 2 vol of SEM buffer and pelleted at $12,000 \mathrm{~g}\left(4^{\circ} \mathrm{C}\right)$.

For two dimensional gel electrophoresis the mitochondrial pellet was resuspended in urea buffer ( $8 \mathrm{M}$ urea, $4 \%(\mathrm{w} / \mathrm{v})$ CHAPS, $40 \mathrm{mM}$ 1,4-dithio-DL-threitol). The protein concentration was determined by standard Bradford method (Biorad). Purity of the obtained mitochondria was checked by western blotting.

\subsection{Western blotting}

Purified mitochondria were lysed in ice-cold RIPA buffer (50 mM Tris- $\mathrm{HCl}$ pH 7.5, $150 \mathrm{mM} \mathrm{NaCl}, 2$ mM EDTA, 1\% NP-40, $1 \mathrm{mM}$ PMSF) with the protease inhibitors cocktail for yeast cells (Sigma). Protein concentration was determined by standard Bradford method (Biorad). Samples $(30 \mu \mathrm{g})$ were separated by $12 \%$ SDS-PAGE and transferred onto PVDF membrane (Millipore). The western blot was performed by using a monoclonal antibody (16G9) against yeast mitochondrial porin1 (A-6449, Molecular Probes) or a monoclonal antibody (22C5) against yeast cytosolic 3-phosphoglycerate kinase (A-6457, Molecular Probes) and a peroxidase-conjugated secondary antibody. The reaction was detected by chemioluminescence with an ECL kit (GE Healthcare).

\subsection{Two-dimensional electrophoresis (2DE)}

Two-dimensional electrophoresis (2DE) was performed using the Immobiline polyacrylamide system. Briefly, $60 \mu \mathrm{g}$ (for the analytical gels) or $500 \mu \mathrm{g}$ (for the preparative gels) of samples grown in 3\% glycerol in exponential phase, were diluted in $350 \mu \mathrm{l}$ of urea buffer plus $0.5 \%(\mathrm{v} / \mathrm{v})$ carrier ampholyte pH 3-10 NL (GE Healthcare) and $0.002 \%$ bromophenol blue and loaded onto a commercial non-linear immobilized $\mathrm{pH}$ gradient from $\mathrm{pH} 3$ to $\mathrm{pH} 10$, of $18 \mathrm{~cm}$ length (GE Healthcare). Isoelectric focusing was carried out on the Ettan $^{\mathrm{TM}}$ IPG phor ${ }^{\mathrm{TM}}$ system (GE Healthcare). IPG strips were then rehydrated for $1 \mathrm{~h}$ at $0 \mathrm{~V}$ and for $8 \mathrm{~h}$ at $30 \mathrm{~V}$, at $16^{\circ} \mathrm{C}$. The strips were focused according to the following electrical conditions at $16{ }^{\circ} \mathrm{C}$ : $200 \mathrm{~V}$ for $1 \mathrm{~h}$, from 300 to $3500 \mathrm{~V}$ in $30 \mathrm{~min}, 3500 \mathrm{~V}$ for $3 \mathrm{~h}$, from 3500 to $8000 \mathrm{~V}$ in $30 \mathrm{~min}$, and 8000 until a total of $80,000 \mathrm{~V} / \mathrm{h}$ was reached. Following IEF separation, the strips were equilibrated with $10 \mathrm{ml}$ of a solution containing $50 \mathrm{mM}$ Tris- $\mathrm{HCl}$ $\mathrm{pH} \mathrm{6.8,} 6 \mathrm{M}$ urea, 30\% (v/v) glycerol, $2 \%(\mathrm{w} / \mathrm{v})$ SDS and $2 \%(\mathrm{w} / \mathrm{v})$ DTE for $12 \mathrm{~min}$ and with $10 \mathrm{ml}$ of a solution containing $50 \mathrm{mM}$ Tris-HCl pH 6.8, $6 \mathrm{M}$ urea, 30\% (v/v) glycerol, 2\% (w/v) SDS, 2.5\% $(\mathrm{w} / \mathrm{v})$ iodoacetamide and a trace of bromophenol blue for $5 \mathrm{~min}$. The IPG strips were then placed on self-casted 12\% SDS-PAGE gels $(18 \mathrm{~cm} \times 20 \mathrm{~cm} \times 1.5 \mathrm{~mm})$ and overlaid with a solution of $0.5 \%(\mathrm{w} /$ v) agarose. The second-dimensional SDS-PAGE was carried out at $40 \mathrm{~mA}$ constant current per gel, at $10^{\circ} \mathrm{C}$, until the dye front reached the bottom of the gels. Analytical gels were stained with ammoniacal silver nitrate as previously described (Hochstrasser et al., 1988). The MS-preparative gels were stained with colloidal coomassie (Vilain et al., 2001).

\subsection{Image acquisition, analysis and statistics}

The stained gels were scanned using an Epson Expression 1680 PRO scanner. Computer-aided 2D image analysis was carried out using the ImageMaster 2D Platinum 6.0 software (GE Healthcare).

Image spots were detected, matched and then manually edited. Gel images of the BY4741 control strain were used as the reference for comparison. Each spot volume was processed by background subtraction and total spot volume normalization. Relative spot volumes $(\% V)(V=$ integration of OD over the spot area; $\% V=V$ single spot $/ V$ total spots) were used for quantitative analyses in order to decrease experimental errors. Data are the average \pm SE of four independent experiments (Table 2). Considering the error range of detection which is determined by evaluating the reproducibility of $2 \mathrm{DE}$ gels, we took a quantitative difference of above 2-fold change as a differential expression. A two-tailed non-paired Student's $t$-test was performed using ORIGIN 6.0 (Microcal Software) to determine if the relative change was statistically significant. Only the spots that differed significantly (a 2-fold increase or decrease and a $p$-value between 0.01 and 0.001 ) were selected for mass spectrometry analysis. The apparent isoelectric points $(\mathrm{p} I)$ and molecular masses of the proteins were calculated with ImageMaster 2D Platinum 6.0 using as reference identified proteins with known parameters.

\subsection{Protein identification by MALDI-TOF mass spectrometry}

Protein spots were manually excised from the gel, washed with high-purity water and with $50 \%$ acetonitrile/water and dehydrated with $100 \%$ acetonitrile. The gel slices were swollen at room temperature in $20 \mu \mathrm{l}$ of $40 \mathrm{mM} \mathrm{NH}_{4} \mathrm{HCO}_{3} / 10 \%$ acetonitrile containing $25 \mathrm{ng} / \mu \mathrm{l}$ trypsin (Trypsin Gold, mass spectrometry grade, Prome-

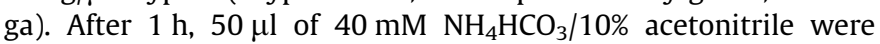
added and digestion proceeded overnight at $37^{\circ} \mathrm{C}$. The generated peptides were extracted with $50 \%$ acetonitrile/5\% trifluoroacetic acid (TFA, two steps, 20 min each at room temperature), dried by 


\begin{tabular}{|c|c|c|c|c|c|c|c|c|c|c|c|c|}
\hline \multirow{2}{*}{$\begin{array}{l}\text { Spot } \\
\text { no. }\end{array}$} & \multirow[t]{2}{*}{ Protein name } & \multirow[t]{2}{*}{$\mathrm{AC}^{\mathrm{d}}$} & \multirow{2}{*}{$\begin{array}{l}\text { Theoretical }{ }^{\mathrm{p}} \mathrm{I} / \mathrm{Mr} \\
\text { (kDa) }\end{array}$} & \multirow{2}{*}{$\begin{array}{l}\text { Experimental } \mathrm{fl} / \mathrm{Mr} \\
(\mathrm{kDa})\end{array}$} & \multirow[t]{2}{*}{$\mathrm{g}$} & \multirow{2}{*}{$\begin{array}{l}\text { No of matching } \\
\text { peptides }^{\mathrm{h}}\end{array}$} & \multirow{2}{*}{$\begin{array}{l}\text { Sequence } \\
\text { coverage }(\%)\end{array}$} & \multicolumn{3}{|c|}{$\% \mathrm{~V}\left(* 10^{-3}\right)$ media $( \pm \mathrm{S} \mathrm{D})^{\mathrm{a}}$} & \multicolumn{2}{|c|}{ Fold change $\mathrm{j}^{\mathrm{j}}$} \\
\hline & & & & & & & & BY4741 & $\Delta \mathrm{Sco} 1$ & $\Delta \mathrm{Sco} 2$ & $\begin{array}{l}\mathrm{BY} / \\
\Delta \mathrm{Sco} 1\end{array}$ & $\begin{array}{l}\mathrm{BY} / \\
\Delta \mathrm{Sco} 2\end{array}$ \\
\hline 1 & Acetyl-CoA hydrolase, ACH1 & P32316 & $6.3 / 58.71$ & $6.5 / 40.00$ & 129 & 8 & 50 & $159 \pm 37$ & $31.5 \pm 5.0^{\mathrm{b}}$ & $165 \pm 27$ & 5.0 & 0.9 \\
\hline 2 & Glycerol-3-phosphate dehydrogenase, GUT2 & P32191 & 7.9/72.39 & $7.0 / 62.77$ & 102 & 20 & 55 & $79 \pm 7$ & $1.5 \pm 0.5^{\mathrm{c}}$ & $77 \pm 9.6$ & 52 & 1.0 \\
\hline 3 & Aspartyl-tRNA synthetase, MSD1 & P15179 & $9.2 / 75.46$ & $8.6 / 64.01$ & 83 & 14 & 35 & $112 \pm 15$ & $16.7 \pm 4.0^{c}$ & $95 \pm 10$ & 6.7 & 1.2 \\
\hline 4 & Cytochrome b-c1 complex subunit 1, COR1 & P07256 & $7.3 / 50.23$ & $6.4 / 47.48$ & 113 & 13 & 42 & $615 \pm 65$ & $151 \pm 49^{c}$ & $652 \pm 71$ & 4.1 & 0.9 \\
\hline 5 & Cytochrome b-c1 complex subunit 7, QCR7 & P00128 & $5.8 / 14.57$ & $5.8 / 13.84$ & 190 & 10 & 45 & $36.7 \pm 8.0$ & $4.3 \pm 2.5^{\mathrm{b}}$ & $50 \pm 20$ & 8.5 & 0.7 \\
\hline 6 & Ubiquinone biosynthesis protein, COQ9 & Q05779 & $9.5 / 29.96$ & $7.8 / 20.76$ & 104 & 12 & 52 & $41.3 \pm 6.0$ & $19.5 \pm 4.0^{\mathrm{b}}$ & $48 \pm 6.6$ & 2.1 & 0.9 \\
\hline 7 & ATP synthase subunit alpha, ATP1 & P07251 & $6.7 / 54.94$ & $6.7 / 16.06$ & 73 & 9 & 40 & $583 \pm 24$ & $263 \pm 35^{c}$ & $466 \pm 31$ & 2.2 & 1.3 \\
\hline 8 & ATP synthase subunit alpha, ATP1 & P07251 & $6.7 / 54.94$ & $6.8 / 31.41$ & 88 & 14 & 58 & $1413 \pm 277$ & $485 \pm 43^{\mathrm{b}}$ & $1041 \pm 303$ & 2.9 & 1.4 \\
\hline 9 & ATP synthase subunit alpha, ATP1 & P07251 & $6.7 / 54.94$ & $6.9 / 56.00$ & 90 & 15 & 34 & $43 \pm 3.4$ & $14 \pm 1.3^{\mathrm{c}}$ & $27 \pm 5.0$ & 2.9 & 1.6 \\
\hline 10 & $\begin{array}{l}\text { ATP synthase subunit beta, ATP2 c-terminal } \\
\text { fragment }\end{array}$ & P00830 & $5.1 / 51.12$ & $5.1 / 14.17$ & 80 & 7 & 32 & $853 \pm 77$ & $188 \pm 30^{c}$ & $577 \pm 38$ & 4.5 & 1.5 \\
\hline 11 & ATP synthase subunit beta, ATP2 & P00830 & $5.1 / 51.12$ & $4.7 / 27.25$ & 102 & 12 & 42 & $219 \pm 28.4$ & $50 \pm 2.0^{c}$ & $186 \pm 63$ & 4.4 & 1.2 \\
\hline 12 & $\begin{array}{l}\text { Outer mitochondrial membrane protein porin } 1 \\
\text { (VDAC 1) }\end{array}$ & P04840 & $7.7 / 30.30$ & $7.7 / 19.15$ & 150 & 10 & 45 & $547 \pm 40$ & $197 \pm 30^{c}$ & $479 \pm 64$ & 2.8 & 1.1 \\
\hline 13 & $\begin{array}{l}\text { Outer mitochondrial membrane protein porin } 1 \\
\text { (VDAC } 1 \text { ) }\end{array}$ & P04840 & $7.7 / 30.30$ & $8.9 / 16.11$ & 111 & 5 & 55 & $356 \pm 95$ & $138 \pm 20^{\mathrm{b}}$ & $414 \pm 102$ & 2.6 & 0.9 \\
\hline 14 & $\begin{array}{l}\text { Outer mitochondrial membrane protein porin } 1 \\
\text { (VDAC 1) }\end{array}$ & P04840 & $7.7 / 30.30$ & 7.9/23.46 & 165 & 11 & 37 & $207 \pm 12$ & $63 \pm 3.7^{c}$ & $154 \pm 29$ & 3.3 & 1.3 \\
\hline 15 & $\begin{array}{l}\text { Outer mitochondrial membrane protein porin } 1 \\
\text { (VDAC 1) }\end{array}$ & P04840 & $7.68 / 30297$ & $7.3 / 23.18$ & 148 & 16 & 52 & $469 \pm 96$ & $193 \pm 37^{b}$ & $342 \pm 34$ & 2.4 & 1.4 \\
\hline 16 & $\begin{array}{l}\text { Outer mitochondrial membrane protein porin } 1 \\
\text { (VDAC1) }\end{array}$ & P04840 & $7.7 / 30.30$ & $6.9 / 24.98$ & 98 & 14 & 40 & $1008 \pm 199$ & $457 \pm 51^{b}$ & $927 \pm 139$ & 2.2 & 1.1 \\
\hline 17 & Heat shock protein SSC1, mtHSP70 & P12398 & $5.2 / 68.09$ & $4.7 / 29.51$ & 87 & 7 & 35 & $44 \pm 7.3$ & $13 \pm 5.0^{\mathrm{b}}$ & $54 \pm 7.3$ & 3.4 & 0.8 \\
\hline 18 & Heatshock protein SSC1, mtHSP70 & P12398 & $5.2 / 68.09$ & $6.78 / 43.82$ & 93 & 13 & 43 & $375 \pm 25$ & $103 \pm 15^{\mathrm{c}}$ & $236 \pm 52$ & 3.6 & 1.6 \\
\hline 19 & GrpE protein homolog, mitochondrial, MGE1 & P38523 & $8.9 / 26.07$ & $5.2 / 20.09$ & 88 & 6 & 44 & $786 \pm 62$ & $361 \pm 51^{\mathrm{c}}$ & $658 \pm 40$ & 2.2 & 1.2 \\
\hline 20 & Citrate synthase, mitochondrial CIT1 & P00890 & $6.5 / 49.21$ & $6.8 / 47.89$ & 81 & 18 & 40 & $70 \pm 2.8$ & $213 \pm 25^{c}$ & $143 \pm 45^{\mathrm{b}}$ & 0.3 & 0.5 \\
\hline 21 & Serine hydroxymethyltransferase, cytosolic, SHM2 & P37291 & $7.4 / 52.22$ & $7.1 / 50.48$ & 68 & 9 & 27 & $189 \pm 41$ & $198 \pm 35$ & $59 \pm 9.0^{\mathrm{b}}$ & 0.9 & 3.2 \\
\hline 22 & Mitochondrial outer membrane protein OM45 & P16547 & $8.5 / 44.58$ & $8.3 / 47.50$ & 83 & 13 & 35 & $165 \pm 31$ & $45 \pm 5.5^{\mathrm{b}}$ & $115 \pm 25$ & 3.7 & 1.4 \\
\hline 23 & NifU-like protein, NUF1 & P32860 & $4.8 / 29.17$ & $4.8 / 28.96$ & 110 & 18 & 44 & $325 \pm 53$ & $56 \pm 5.7^{b}$ & $177 \pm 24$ & 5.8 & 1.8 \\
\hline 24 & Cysteine desulfurase NFS1 & P25374 & $8.3 / 54.47$ & $6.9 / 51.71$ & 77 & 13 & 36 & $62 \pm 6.0$ & $31 \pm 4.0^{\mathrm{b}}$ & $27 \pm 3.0^{\mathrm{c}}$ & 2.0 & 2.3 \\
\hline 25 & Homo-isocitrate dehydrogenase, LYS12 & P40495 & $8.1 / 40.07$ & $6.6 / 41.29$ & 81 & 8 & 18 & $72 \pm 8.8$ & $28 \pm 2.2^{\mathrm{b}}$ & $55 \pm 5.2$ & 2.6 & 1.3 \\
\hline 26 & Alpha subunit of succinyl-CoA ligase, LSC1 & P53598 & $8.7 / 35.03$ & $6.8 / 29.23$ & 78 & 7 & 39 & $172 \pm 26$ & $68 \pm 4.0^{\mathrm{b}}$ & $183 \pm 27$ & 2.5 & 0.9 \\
\hline 27 & Alpha subunit of succinyl-CoA ligase, LSC1 & P53598 & $8.7 / 35.03$ & $6.7 / 30.10$ & 94 & 14 & 57 & $74 \pm 8.3$ & $22 \pm 2.7^{\mathrm{c}}$ & $96 \pm 16$ & 3.4 & 0.8 \\
\hline 28 & Malate dehydrogenase, mitochondrial MDH1 & P17505 & $6.8 / 33.83$ & $7.0 / 35.86$ & 113 & 10 & 43 & $637 \pm 116$ & $219 \pm 17^{\mathrm{b}}$ & $541 \pm 125$ & 2.9 & 1.2 \\
\hline 29 & $\begin{array}{l}\text { Mitochondrial external NADH dehydrogenase } 1 \text {, } \\
\text { NDE1 }\end{array}$ & P40215 & $10 / 62.77$ & $8.9 / 58.07$ & 100 & 20 & 40 & $214 \pm 46$ & $78 \pm 7.0^{\mathrm{b}}$ & $153 \pm 38$ & 2.7 & 1.4 \\
\hline 30 & Probable 2-methylcitrate dehydratase, PDH1 & Q12428 & $9.8 / 57.68$ & $8.9 / 52.54$ & 65 & 7 & 30 & $314 \pm 73$ & $80 \pm 1.8^{\mathrm{b}}$ & $206 \pm 24$ & 3.9 & 1.5 \\
\hline 31 & Alkyl HydroPeroxide reductase, AHP1 & P38013 & $4.9 / 19.12$ & $4.8 / 17.60$ & 94 & 6 & 40 & $177 \pm 28$ & $363 \pm 52^{\mathrm{b}}$ & $142 \pm 30$ & 0.5 & 1.2 \\
\hline 32 & Mitochondrial superoxide dismutase, SOD2 & P00447 & $6.1 / 23.08$ & $7.3 / 21.16$ & 89 & 7 & 44 & $1500 \pm 300$ & $540 \pm 60^{\mathrm{b}}$ & $1010 \pm 82$ & 2.8 & 1.5 \\
\hline 33 & Flavohemoprotein, YHB1 & P39676 & $6.3 / 44.65$ & $6.2 / 44.26$ & 111 & 13 & 42 & $115 \pm 19$ & $297 \pm 39^{\mathrm{b}}$ & $79 \pm 9.2$ & 0.4 & 1.5 \\
\hline 34 & Flavohemoprotein, YHB1 & P39676 & $6.3 / 44.65$ & $6.0 / 44.28$ & 82 & 10 & 33 & $28 \pm 5$ & $114 \pm 20^{\mathrm{b}}$ & $27 \pm 5.8$ & 0.3 & 1.0 \\
\hline 35 & Subunit of the prohibitin complex, PHB1 & P40961 & $8.9 / 31.43$ & $7.8 / 26.56$ & 159 & 8 & 31 & $678 \pm 11$ & $293 \pm 38^{\mathrm{b}}$ & $544 \pm 11$ & 2.3 & 1.2 \\
\hline
\end{tabular}

Each value represents the mean $\pm S D$ of individually computed $\% \mathrm{~V}(\mathrm{~V}=$ integration of OD over the spot area; \% $=\mathrm{V}$ single spot/ $\mathrm{V}$ total spot $)$ in gels of four independent experiments for each yeast strain.

$p$-Value $\leqslant 0.01$.

d $p$-Value $\leqslant 0.001$.

e Predicted $\mathrm{pl}$ and $\mathrm{Mr}$ according to protein sequence.

${ }_{\mathrm{f}}$ Measured pI and Mr values were experimentally determined with ImageMaster 2D Platinum 6.0 using identified proteins with known parameters as a reference.

g MASCOT score (Matrix Science, London, UK; http://www.matrixscience.com)

Number of peptide masses matching the top hit from Ms-Fit PMF.

Percentage of amino acid sequence coverage of matched peptides in the identified proteins.

${ }^{j}$ Fold change (wild type strain versus each deletion mutant strain) was calculated dividing \%V from BY4741 yeast strain by the \%V from sco1- $\Delta$ or $s c 02-\Delta$ mutant. 
vacuum centrifugation, suspended in $0.1 \%$ TFA, passed through micro ZipTip C18 pipette tips (Milllipore, Bedford, MA, USA) and directly eluted with the MS matrix solution $(10 \mathrm{mg} / \mathrm{ml} \alpha$-cyano-4hydroxycinnamic acid in 50\% acetonitrile/1\% TFA). Mass spectra of the tryptic peptides were obtained using a Voyager-DE MALDITOF mass spectrometer (Applied Biosystems). Peptide mass fingerprinting database searching was performed using MASCOT search engine (http://www.matrixscience.com) in the NCBInr/Swiss-Prot databases. Parameters were set to allow one missed cleavage per peptide, a mass tolerance of $0.5 \mathrm{Da}$ and to consider carbamidomethylation of cysteines as a fixed modification and oxidation of methionines as a variable modification. The criteria used to accept identifications included the extent of sequence coverage, the number of matched peptides and the probabilistic score, as detailed in Table 2.

\subsection{Analysis of protein function}

Information about the function of identified proteins was obtained from the SWISS-PROT (http://www.expasy.org/sprot/), SGD (genome-http://www.stanford.edu/Saccharomyces/) and MITOP2 (http://www.mitop2.de) databases.

\section{Results}

\subsection{Characterization of the strains}

Previous studies have shown that the sco1- $\Delta$ mutant exhibits growth defect on respiratory carbon sources such as glycerol and ethanol. Our studies confirmed this phenotype: in 3\% glycerol this yeast mutant strain duplicated only once within $24 \mathrm{~h}$ after which it stopped growth (Fig. 1A). On $2 \%$ ethanol the sco1- $\Delta$ mutant's growth defect was more evident as the duplication time increased of up to $30 \mathrm{~h}$ compared to the control strain (Fig. 1B). Regarding the sco2- $\Delta$ mutant strain, in $2 \%$ ethanol its growth rate was similar to the sco1- $\Delta$ mutant strain throughout the first $24 \mathrm{~h}$. After $24 \mathrm{~h}$ its growth rate increased and at $36 \mathrm{~h}$ cell density in the $s c 02-\Delta$ mutant and in the wild type strains was identical. In $3 \%$ glycerol, the growth rate of the sco2- $\Delta$ mutant was comparable to the control strain. On medium containing $0.5 \%$ glucose, the growth rate was the same for the three yeast strains during the exponential phase, but the sco1- $\Delta$ mutant reached a lower cell density in stationary phase (Fig. 1C). In particular, sco1- $\Delta$ mutant arrested its growth after approximately $10 \mathrm{~h}$ when the yeast cells shifted from a fermentative to a respiratory metabolism (diauxic shift).
A

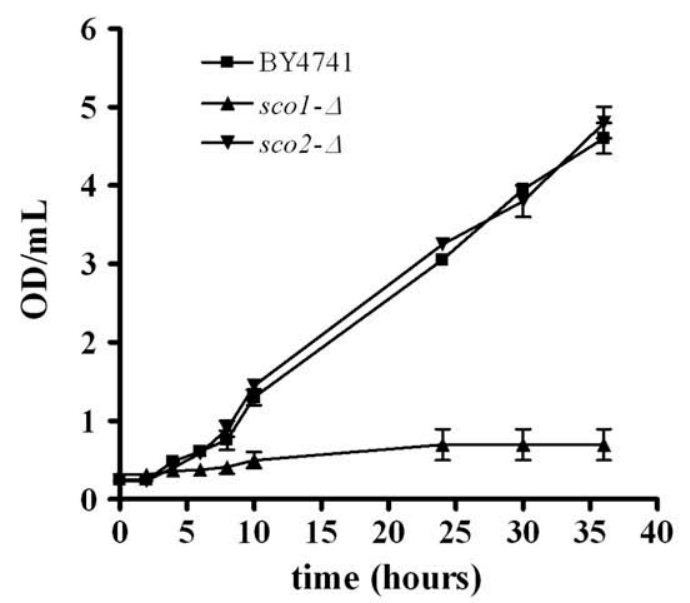

B

\section{$2 \%$ ethanol}

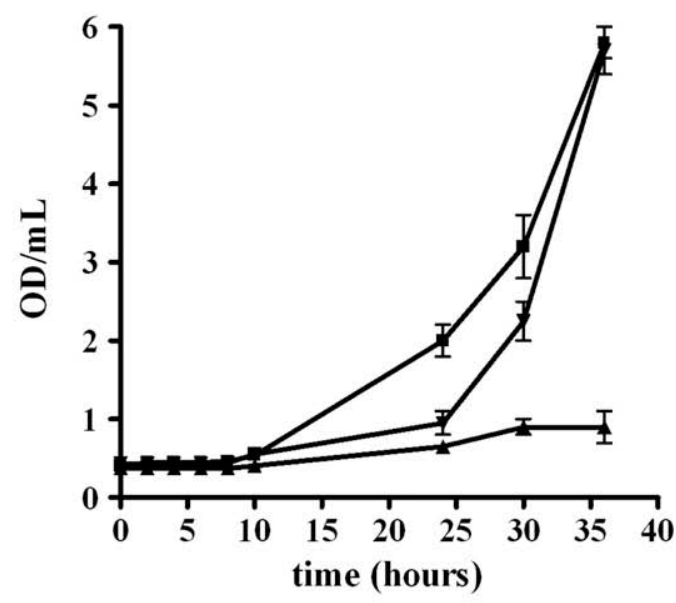

C

$0.5 \%$ glucose

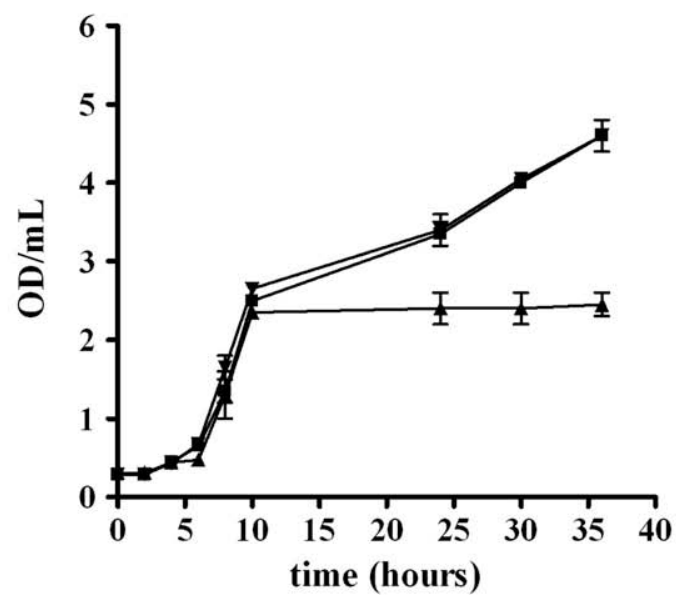

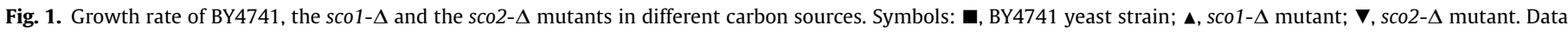
represent mean and standard deviation obtained from three independent experiments. 
In order to evaluate if SCO1 and SCO2 deletions affected yeast cell fitness on different carbon sources, we examined the viability of the three yeast strains during chronological aging by measuring the percentage of colony-forming units (c.f.u.) on media containing $2 \%$ glucose, $20 \%$ glucose, $2 \%$ galactose, $3 \%$ glycerol or $0.5 \%$ glucose as carbon sources. The sco1- $\Delta$ mutant strain displayed a reduced fitness in all growth condition in comparison to the sco2- $\Delta$ mutant and the wild type strains. In particular on media containing $2 \%$ glucose, the sco1- $\Delta$ mutant strain died after 10 days, whereas $10 \%$ of the cells in the sco2- $\Delta$ mutant and the wild type strains were still viable (Fig. 2A). The same results were obtained on medium containing $20 \%$ glucose (data not shown). This effect is more pronounced on $2 \%$ galactose; in fact, after 6 days the sco1- $\Delta$ mutant is no longer viable whereas the viability of BY4741 and the sco2$\Delta$ mutant is approximately $50 \%$ (Fig. $2 \mathrm{~B}$ ). On $0.5 \%$ glucose the sco1- $\Delta$ mutant strain died after 10 days whereas $40 \%$ of the cells in the sco2- $\Delta$ mutant and the wild type strains were still viable (Fig. 2C). On 3\% glycerol, the sco1- $\Delta$ mutant strain's lifespan is longer than that in the other growth conditions but it is still shorter in comparison to the other two strains. In fact, after 14 days, whilst $60 \%$ of the cells in the $\operatorname{sco} 2-\Delta$ mutant and the wild type strains were still viable, the sco1- $\Delta$ mutant strain died (Fig. 2D). Viability was also assessed by using FUN-1 [2-chloro-4-(2,3-dihy- dro-3-methyl-(benzo-1,3-thiazol-2-yl)-methylidene)-1-phenylquinolinum iodide] staining (Millard et al., 1997). The results obtained were comparable to those obtained from the plate counts (data not shown).

\subsection{Ethanol production}

We addressed the question on whether deletion of SCO1 had any effect on the rate of glycolysis and the consequent ethanol production. It is known that yeast mutants with a respiratory-deficient phenotype exhibit higher rates of fermentation because they are not subject to the Pasteur effect, i.e. the oxygen suppression of glycolysis. On the contrary, they have a reduced tolerance to ethanol in comparison to parental strains. These data together with our results suggest that the reduced lifespan of the sco1- $\Delta$ mutant on media containing fermentable carbon sources, could be due to the high rate of fermentation and the subsequent high concentration of ethanol reaching that reaches toxic level. We then assayed ethanol production during growth on $2 \%$ glucose and on $2 \%$ galactose during exponential phase and after $24 \mathrm{~h}$. As shown in Fig. 3, the average results, based on four independent experiments, indicate a higher fermentative capacity of the sco1- $\Delta$ mutant cells in comparison to the control cells and sco2- $\Delta$ mutant cells both on $2 \%$ glucose
A

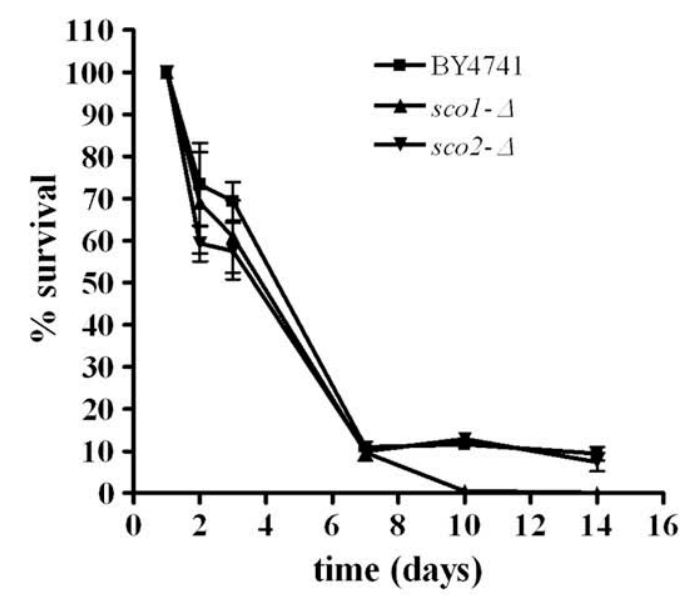

C

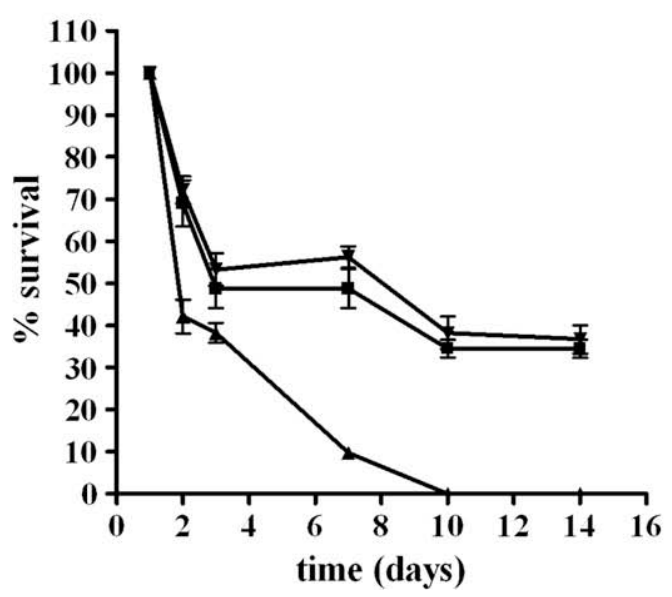

B

\section{$2 \%$ galactose}

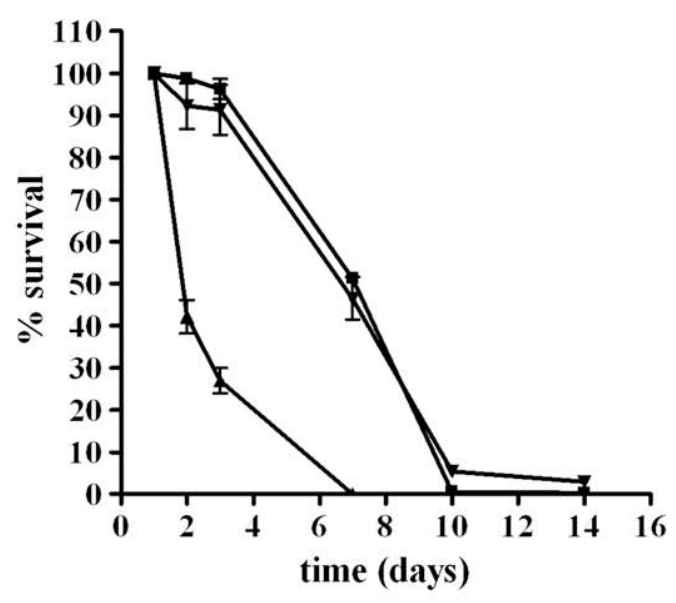

D

\section{3\% glycerol}

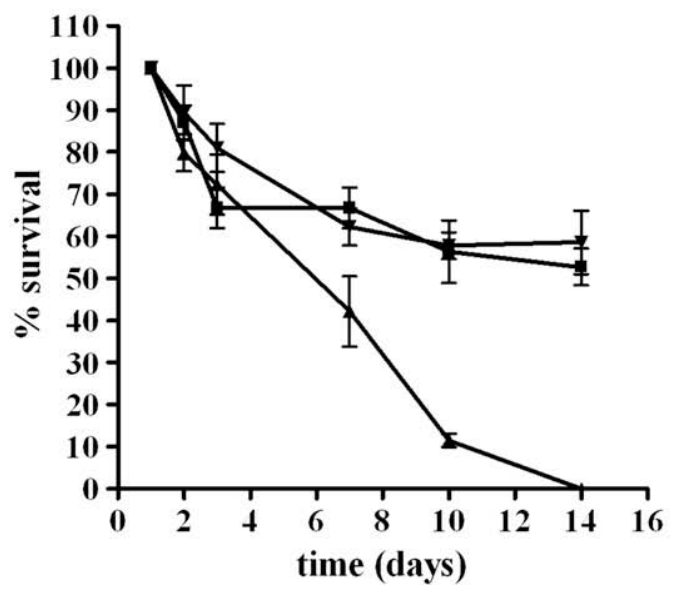

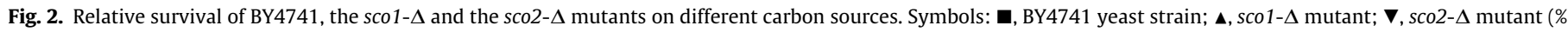

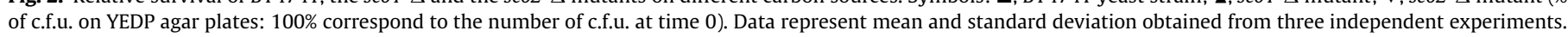


and $2 \%$ galactose. The ethanol production in the sco1- $\Delta$ mutant during exponential growth on glucose was 2.5 -fold higher than in the wild type and about 3-fold higher than in the sco2- $\Delta$ mutant. After $24 \mathrm{~h}$ the ethanol production showed a reduction as the cells entered stationary phase and there were no significant differences between the three strains (panel A). On galactose, the ethanol production was lower than on glucose in all strains. Nevertheless, during the exponential phase, even in this condition the sco1- $\Delta$ mutant displayed a productivity 4-fold higher than both the sco2- $\Delta$ mutant and the wild type strains. At $24 \mathrm{~h}$ there were no differences between these strains (panel B). We also investigated the effect of SCO1 deletion on the rate of ethanol fermentation on $20 \%$ glucose as carbon source in order to make the medium more similar to natural must. We then studied the effect of Sco1p deletion on the rate of fermentation on molasses, by-product of saccharification which is normally used in the industrial production of ethanol. Molasses contain large amount of various sugars including glucose, fructose and sucrose. As shown in Fig. $3 C$ and D, even in these growth conditions the sco1- $\Delta$ mutant displayed a higher productivity in comparison with the $\operatorname{sco} 2-\Delta$ mutant and wild type strains. On $20 \%$ glucose both in exponential and in stationary phase the ethanol production in the sco1- $\Delta$ mutant was 2-fold higher than in the other two yeast strains (Fig. 3C). On molasses, during the exponential phase, the sco1- $\Delta$ mutant displayed an ethanol production 2-fold higher than the sco2- $\Delta$ mutant and the wild type strain as shown in panel D. Moreover at $24 \mathrm{~h}$ its productivity was only 1.7-fold higher in comparison to BY4741 and sco2- $\Delta$.

\subsection{Mitochondrial membrane potential and morphology}

As suggested by our data reported above and by many published papers, Sco1p, unlike Sco2p, is required for proper functioning of mitochondria. We tested a possible defective membrane potential in the sco1- $\Delta$ mutant by observing the accumulation in the cells of the rhodamine B hexyl ester (Rhodamine B) (Reungpatthanaphong et al., 2003) by confocal microscopy. Cells were cultivated on $2 \%$ glucose and $3 \%$ glycerol. After $24 \mathrm{~h}$ of growth the deletion mutants and the isogenic strain were examined. On $2 \%$ glucose each strain showed a similar staining pattern, indicating an intact membrane potential (Supplementary Fig. 1A). On the con-
A

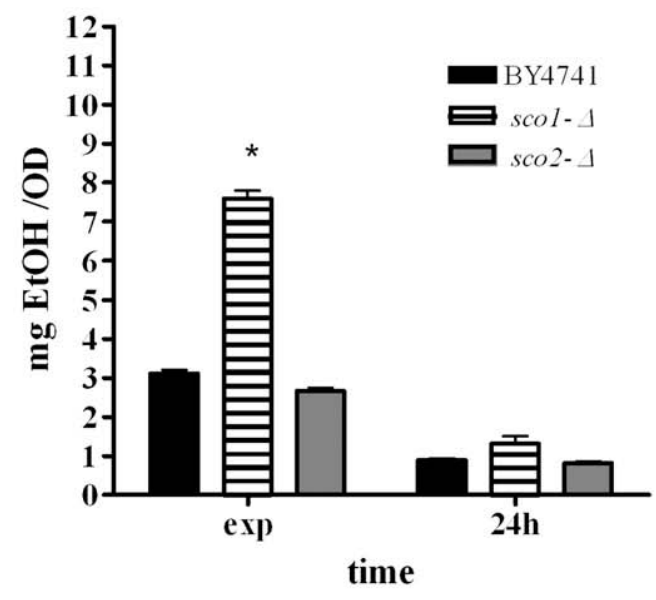

C
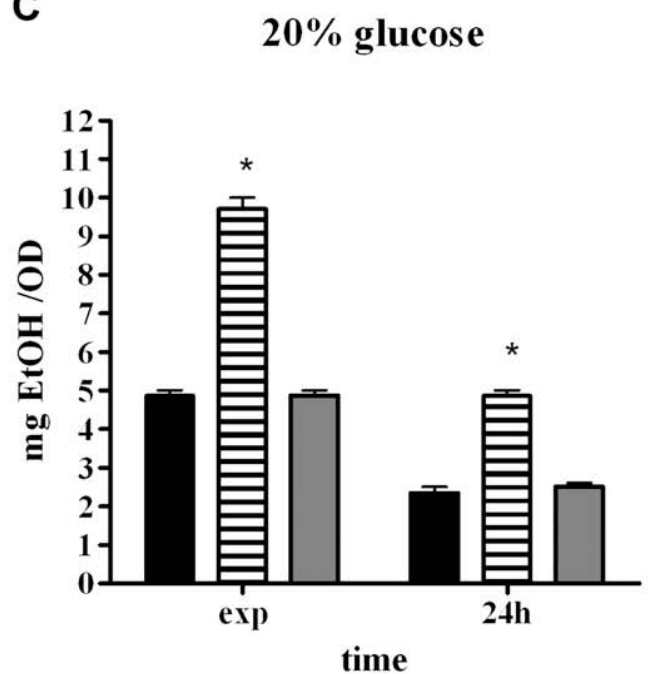

B $2 \%$ galactose

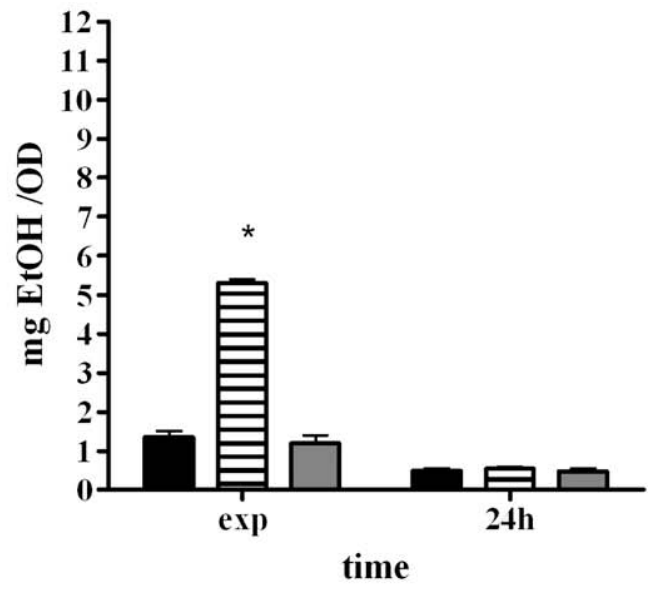

D

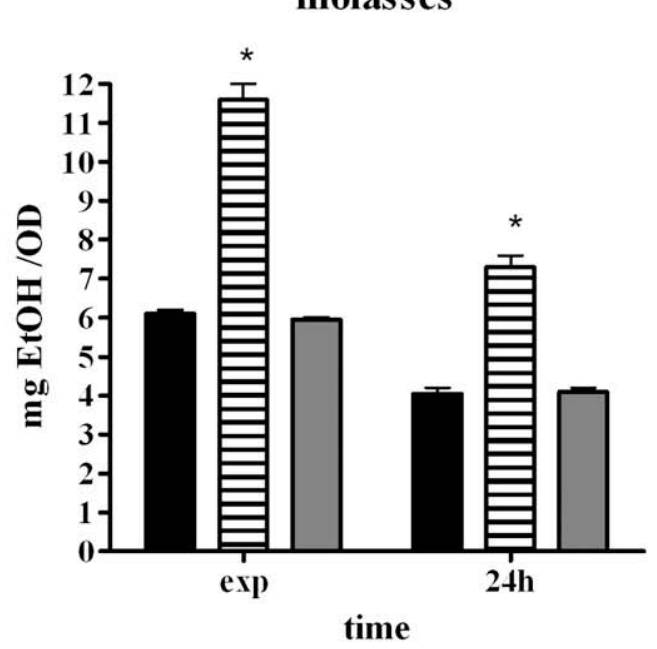

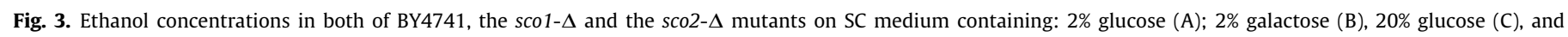

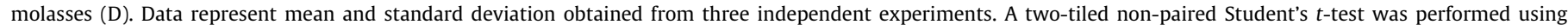

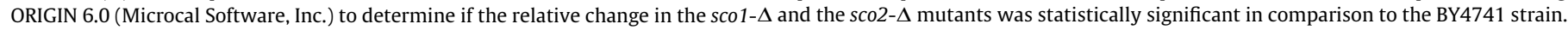
Differences were considered statistically significant when $p<0.01(*)$. 
trary, on 3\% glycerol (Supplementary Fig. 1B), cells from the sco1- $\Delta$ mutant strain showed a diffused staining pattern with no clear rhodamine accumulation in the inner mitochondrial membrane. This might indicate a loss of mitochondrial membrane potential in the sco1- $\Delta$ mutant cells. Since an abnormal mitochondrial morphology is associated with many respiratory-deficient mutants (Petrezselyova et al., 2008), we analyzed the morphology of mitochondria in the three yeast strains using the plasmid pYX142mitoGFP that allows GFP to be specifically located in the membrane of these organelles (Westermann and Neupert, 2000). It is known that mitochondria structure changes depending on the medium: on a non-fermentable carbon source they are numerous and small (punctate structures), whereas on a rich glucose medium they are few, large and branched (mitochondria reticula) (Visser et al., 1995; García-Rodríguez et al., 2007). Mitochondria morphology on $2 \%$ glucose (Fig. $4 \mathrm{~A}$ ) during the first $24 \mathrm{~h}$ was similar in all strains and acquired the mitochondria reticula form. In addition, the number of GFP-labelled yeast cells was similar between all strains as reported in the histograms in Fig. 4C. They exhibited approximately $80 \%$ of GFP-labelled cells. On 3\% glycerol (panel $\mathrm{B})$, mitochondria morphology in the sco2- $\Delta$ mutant and the wild type strains changed to the punctate structure typical of a derepressed state, whilst in the sco1- $\Delta$ mutant strain, the spots are still small but few. Moreover, in this strain the number of GFP-labelled yeast cells was drastically lower in comparison to the control and the sco2- $\Delta$ mutant strains (Fig. $4 C$ ). In fact, only the $40 \%$ of cells in the sco1- $\Delta$ mutant strain were GFP-labelled. On the other hand, approximately $90 \%$ of cells in the control and sco2- $\Delta$ mutant strains were GFP-labelled. The level of rhodamine accumulation and the different morphological proprieties likely indicate that the sco1- $\Delta$ mutant strain is not proficient in maintaining or in reproducing functional mitochondria.

\subsection{Mitochondrial proteomic analysis}

To check whether the lack of Sco1p affects the expression of specific mitochondrial proteins during exponential phase on respirable carbon sources, we compared the pattern of mitochondrial proteomes in sco1- $\Delta$ and sco2- $\Delta$ mutants with the pattern of mitochondrial proteomes in wild type cells. Mitochondria were purified from sco1- $\Delta$ and sco2- $\Delta$ cell cultures and from the control strain grown on glycerol, as described in Section 2.6. The purity obtained is crucial for subsequent proteome analyses, hence we monitored it by western blotting with anti-mitochondrial porin 1 (mitochondrial marker protein) and anti-3-phosphoglycerate kinase (PGK) antibody for detection of citoplasmic contamination. This analysis (Fig. 5A) showed the high degree of purity of these preparations. Proteins purified from mitochondria preparations were resolved by two-dimensional electrophoresis and the resulting electropherograms were analyzed using the ImageMaster 2D Platinum 6.0
A

BY4741
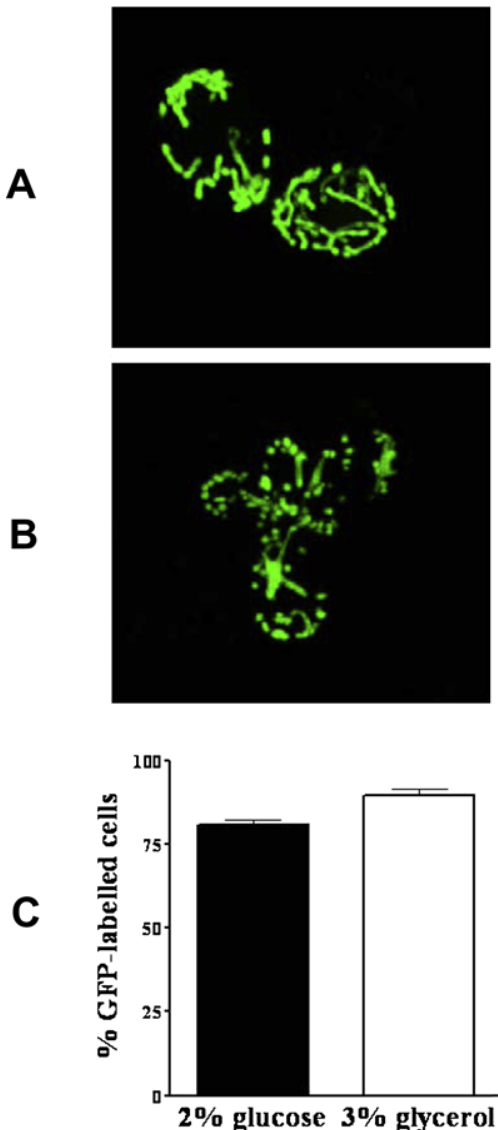

$\operatorname{scol}-\Delta$
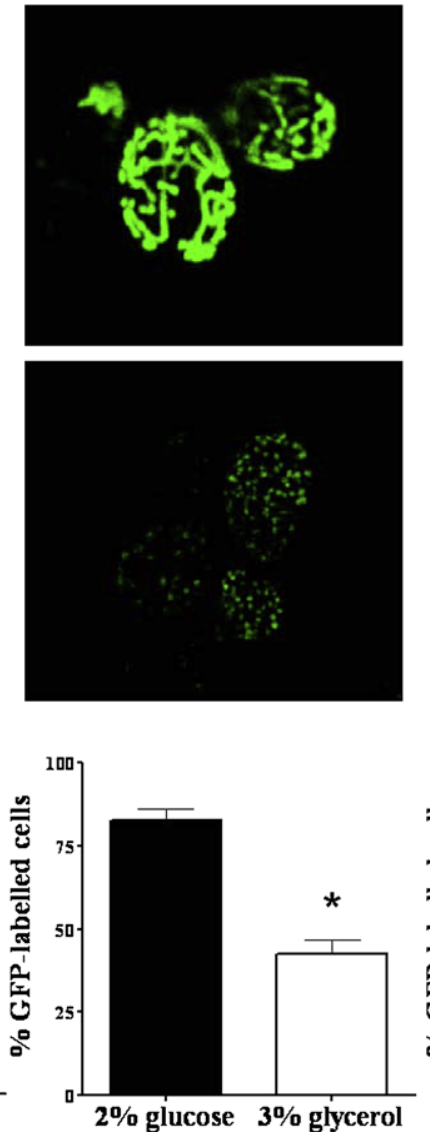

$\operatorname{sco} 2-\Delta$
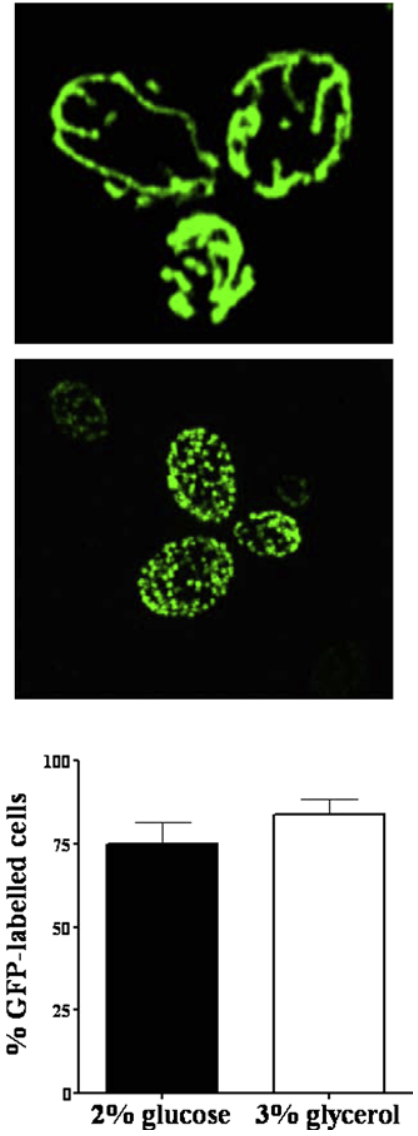

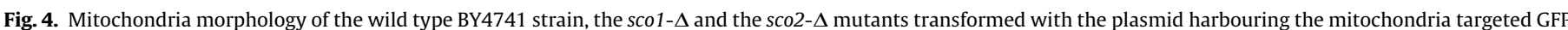

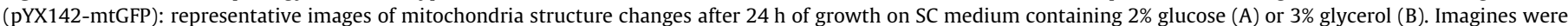

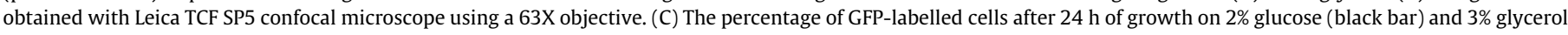

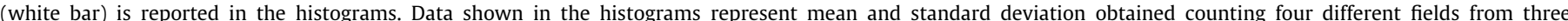

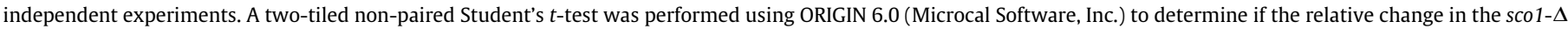
and the $\operatorname{sco} 2-\Delta$ mutants was statistically significant in comparison to the BY4741 strain. Differences were considered statistically significant when $p<0.01(*)$. 
A
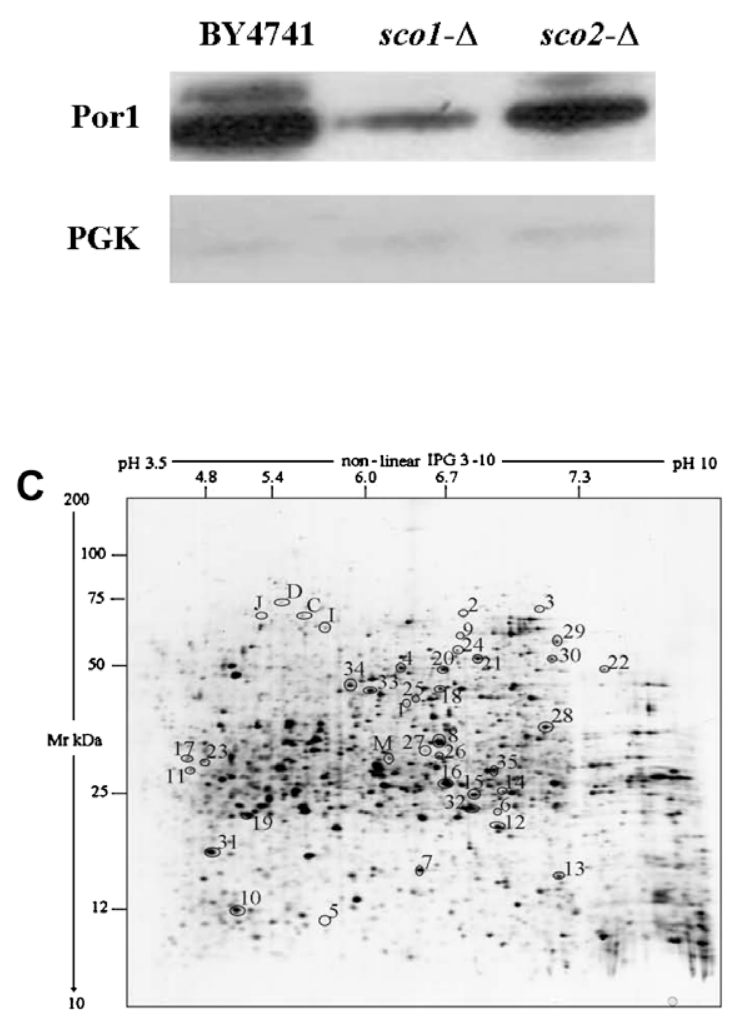
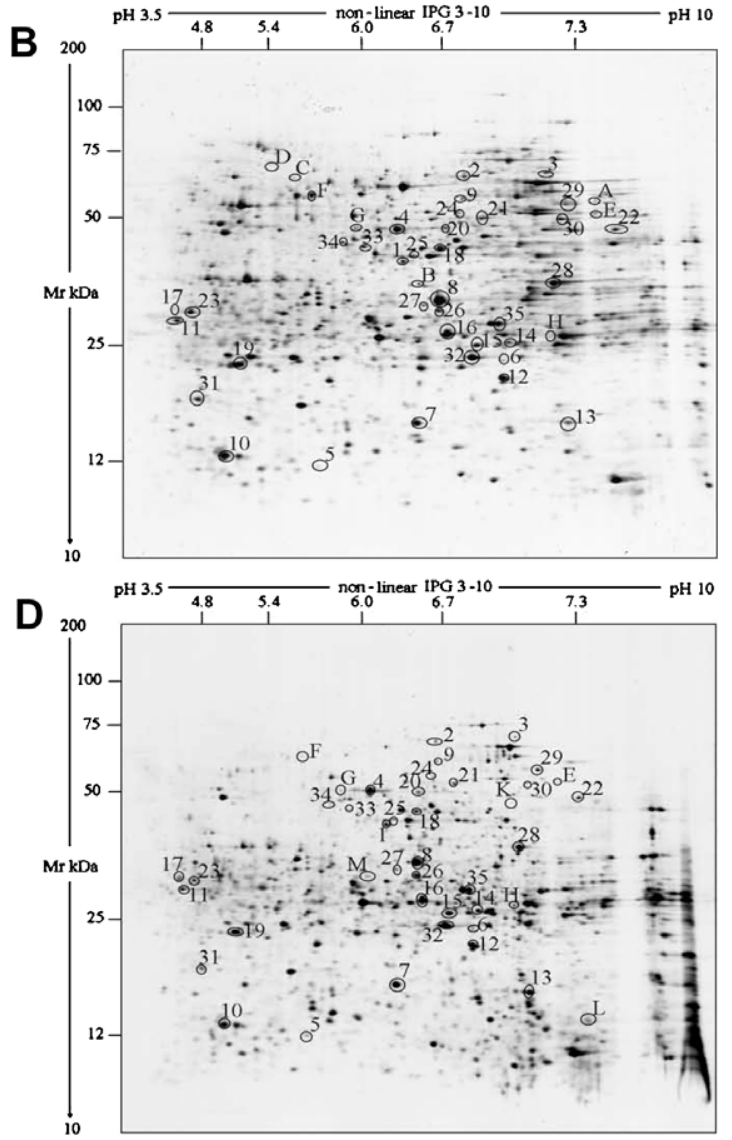

Fig. 5. Mitochondrial proteome of the wild type BY4741 strain, the sco1- $\Delta$ and the sco2- $\Delta$ mutants. (A) Western blot analysis of purified $S$. cerevisiae mitochondria of BY4741, the sco1- $\Delta$ and the sco2- $\Delta$ mutants after $24 \mathrm{~h}$ of growth on SC medium with 3\% glycerol. Mitochondria were purified as descried by Meisinger et al. (2000). See Section 2.6 for details. The samples were separated on a SDS-PAGE and blotted onto PVDF membranes as described. Detection of the immunosignals was done using the ECL System (Amersham). Equal amounts of proteins are loaded representing the enrichment of a specific mitochondrial protein Por1 compared to a cytosolic protein PGK. Representative 2DE silver-stained gels of mitochondrial proteins extract from BY4741 (B), the $\operatorname{sco1}-\Delta$ (C) and the $s c 02-\Delta$ (D) mutants. Quantitative and qualitative variations between control, the sco1- $\Delta$ or the sco2- $\Delta$ cells are displayed by circles. Numbers identify proteins that are present in both gels but display a different expression level. They are listed in Table 2. Qualitative variations identified are displayed by capital letters and represent spots that are not present in all strains as described in Sections 3.4 and 3.6. They are listed in Table 3.

software. In Fig. 5 representative 2DE images of soluble yeast mitochondrial proteins from control cells (panel B), sco1- $\Delta$ (panel C) and $\operatorname{sco} 2-\Delta$ (panel D) mutants are reported. The computer analysis pointed out a total of 48 protein spots that had changed significantly. Among these spots 35 were differentially expressed (quantitative differences indicated as circles with numbers in Fig. 5) whereas 14 were not detected in all the analyzed strains (qualitative differences indicated as circles with capital letters in Fig. 5). The protein expression variation of specific proteins was considered significant if the corresponding spots changed more than 2fold in relative volume $(\% \mathrm{~V})$. Identification of these proteins was carried out by MALDI-TOF mass spectrometry. Quantitative and qualitative analyses were obtained from four independent mitochondrial preparations for each strain after growth on glycerol. Between 800 and 840 intense spots were detected in each silverstained two-dimensional gel. This general pattern was maintained in all replicate gels thus indicating the high degree of reproducibility of mitochondria purification and 2D procedures. The pattern and relative abundance of proteins present in our gels correspond well to a two-dimensional reference gel for this organelle proteome available at http://www.biochem.oulu.fi/proteomics/ (Ohlmeier et al., 2004).

Moreover, among the 48 protein spots identified, three (spots 21 , 31 and $\mathrm{D}$ ) are cytosolic proteins and only one is a peroxisomal protein (spot A), indicating a good degree of mitochondrial purification.

\subsection{Identification of differentially expressed mitochondrial proteins}

Among 35 differentially expressed proteins which statistically showed significant differences in their expression levels ( $p$-value between 0.01 and 0.001 ), four of them were up-regulated versus the control strain in the sco1- $\Delta$ mutant (spots $20,31,33,34$ ), and one (spot 20 ) in the sco2- $\Delta$ mutant; whereas 30 spots were down-regulated in comparison to the control strain in the sco1- $\Delta$ mutant (spots 19, 22-30, spot 32 and 35) and two in the sco2- $\Delta$ mutant (spot 21 and 24). Finally, in the sco1- $\Delta$ mutant only one spot (spot 21) was expressed similarly to the control strain, whereas in the sco2- $\Delta$ mutant 32 spots showed the same trend of the isogenic strain. This suggests that decrease in the expression level of a number of specific proteins of the sco1- $\Delta$ mutant is a dominant phenomenon as result of SCO1 disruption. The identities of the proteins found are summarized in Table 2 and their locations are marked with numbers in representative gels shown in Fig. 5 (panels B-D). Some of the differentially expressed proteins were present in multiple forms, thus suggesting post-translational modification and/or proteolysis of the corresponding native proteins. We identified three spots (spots 7-9) corresponding to the ATP synthase subunit alpha, two spots (spots 10 and 11) corresponding to the ATP synthase subunit beta, five spots (spots 12-16) corresponding to the outer mitochondrial membrane protein porin 1 (VDAC 1) Por1p, two spots (spots 17 and 18) corresponding to 
the heat shock protein Ssc1 (mtHSP70), two spots (spots 26 and 27) corresponding to the alpha subunit of succinyl-CoA ligase Lsc1 and two spots (spots 33 and 34) corresponding to the flavohemoprotein Yhb1. A lowered $\mathrm{pI}$ together with a slightly decreased molecular mass indicates a cleavage of the mitochondrial targeting sequence (MTS) (Millar et al., 2001). Proteins with significantly decreased molecular masses in our two-dimensional gels indicate protein fragmentation as described for other mitochondrial preparations (Bardel et al., 2002; Fountoulakis et al., 2002).

\subsection{Identification of qualitative differences}

The computer analysis pointed out a total of 13 qualitative spot variations between control cells, sco1- $\Delta$ and $s c 02-\Delta$ mutants. These spots were all identified by MS and the data were summarized in Table 3. Their locations are marked with capital letters in representative gels shown in Fig. 5 (panels B-D). Among these qualitative differences, two spots (spots A and B, Fig. $5 B$ ) were detected exclusively in the control strain, two spots (spots $C$ and D, Fig. 5B and $C$ ) were detected in control strain and in the sco1- $\Delta$ mutant whilst four spots (spots E-H, Fig. 5B and D) were detected both in the control strain and the sco2- $\Delta$ mutant. Two spots were detected exclusively in mitochondria respectively from the sco1- $\Delta$ mutant (spots I and J, Fig. 5C) and the sco2- $\Delta$ mutant (spots K and L, Fig. 5D). Only one protein spot was expressed both in sco1- $\Delta$ and sco2- $\Delta$ mutants and was not detectable in the control strain (spot M, Fig. 5C and D).

\subsubsection{Proteins detected exclusively in the mitochondria of the control} yeast (BY4741)

Among the two proteins (spots A and B, Fig. 5B) whose expression resulted inhibited in $s c 01-\Delta$ and $s c 02-\Delta$ mutants we identified by mass spectrometry the peroxisomal AMP-binding protein, Fat $2 \mathrm{p}$ and the dihydroxyacid dehydratase (Ilv3p). This enzyme is involved in the isoleucine biosynthesis and catalyzes the third step in the common pathway leading to biosynthesis of branched-chain amino acids.

\subsubsection{Proteins detected exclusively in the mitochondria of BY4741 and mutant sco1- $\Delta$}

The mass spectrometry analysis identified these spots (Fig. 5B and $C$ ) as the alpha-isopropylmalate synthase, Leu4p (spot C), which is the main isozyme responsible for the first step in the leucine biosynthesis pathway, and as the cytosolic heat shock protein Sti1p (spot D).

\subsubsection{Proteins detected exclusively in the mitochondria of BY4741 and mutant sco2- $\triangle$}

Four spots (Fig. 5B and D) were detected only in the control and the sco2- $\Delta$ mutant strains. This group includes the protoporphyrinogen oxidase, Hem14p (spot E) that catalyzes the conversion of protoporphyrinogen IX to protoporphyrin IX in the heme biosynthetic pathway; the mitochondrial aldehyde dehydrogenase, Ald4p (spot F), required for growth on ethanol and conversion of acetaldehyde to acetate; the E1 alpha subunit (spot G) and the dihydrolipoamide acetyltransferase component (E2), Lat1p (spot $\mathrm{H}$ ) of the pyruvate dehydrogenase (PDH) complex that catalyzes the direct oxidative decarboxylation of pyruvate to acetyl-CoA.

\subsubsection{Proteins detected exclusively in the mitochondria of mutant sco1- 4}

Two spots were detected exclusively in the sco1- $\Delta$ mutant strain (Fig. 5C). The mass spectrometry analysis identified these spots as D-lactate dehydrogenase, Dld1p (spot I) that oxidizes D-lactate to pyruvate and as cytosolic aldehyde dehydrogenase, Ald6p (spot J) which is required for the conversion of acetaldehyde to acetate. This enzyme migrates to the mitochondrial outer surface under oxidative stress.

\subsubsection{Proteins detected exclusively in the mitochondria of mutant} sco2- $\triangle$

We also detected two exclusive spots in the sco2- $\Delta$ mutant (Fig. 5D). They were identified by mass spectrometry as the subunit of mitochondrial $\mathrm{NAD}(+)$-dependent isocitrate dehydrogenase Idh1p (spot K), which catalyzes the oxidation of isocitrate to alphaketoglutarate in the TCA cycle, and the mitochondrial DNA-binding protein Abf2p (spot L) which is involved in mitochondrial DNA replication and recombination.

\subsubsection{Proteins exclusively detected in the mitochondria of mutants sco1- $\Delta$ and sco2- $\Delta$}

The analysis of the 2DE gels revealed that only one spot was exclusively present in both sco1- $\Delta$ and sco2- $\Delta$ mutants (Fig. $5 \mathrm{C}$ and $\mathrm{D}$ ): the putative mitochondrial aconitase isozyme, Aco2p (spot $\mathrm{M}$ ) that shows similarity to Aco1p, an aconitase required for the TCA cycle.

\section{Discussion}

In this study, we investigated the function of Sco1p and Sco2p by systematically comparing the phenotypes and the mitochondrial proteome of wild type BY4741 and $s c 01-\Delta$ and sco2- $\Delta$ yeast strains. The sco1- $\Delta$ mutant strain exhibited a reduced growth on media containing non-fermentable carbon sources and a reduced fitness both on fermentable and non-fermentable carbon sources in comparison to the wild type and the sco2- $\Delta$ mutant strains. In addition, the sco1- $\Delta$ but not the sco2- $\Delta$ mutant showed a higher ethanol production during growth on various fermentable carbon sources such as $2-20 \%$ glucose, $2 \%$ galactose and molasses. This behaviour is common in yeast mutants with a respiratory-deficient phenotype that exhibit higher rates of fermentation because they are not subject to the Pasteur effect. Moreover the sco1- $\Delta$ mutant cells lacked mitochondrial membrane potential during growth on glycerol. In addition, the microscopic observation of mitochondria-targeted GFP on a non-fermentable carbon source such as glycerol, showed a diffused staining pattern with no mitochondrial network in the sco1- $\Delta$ mutant and a decrease of the number of GFP-labelled yeast cells, thus indicating a decrease of these organelles. All these data, together with that gathered from literature, pointed out that only the absence of SCO1 in the yeast $S$.cerevisiae BY4741 strain lead to a respiratory-deficient phenotype. The proteome analysis confirmed the phenotypic data reported above, showing that the absence of Sco1p has a more pronounced effect on the mitochondrial proteome than the deletion of SCO2. In the sco1- $\Delta$ mutant strain we found a decrease in the expression level of many mitochondrial proteins in comparison to the wild type and the $s c 02-\Delta$ mutant strains. These proteins could be grouped in different functional classes: energy metabolism, C-compound and carbohydrate metabolism, protein and amino acid biosynthesis, protein translocation and folding, transport of metabolites, iron metabolism, oxygen and reactive oxygen species metabolism and other (unknown) function.

Among the identified proteins that are down-regulated in the sco1- $\Delta$ mutant strain, most are involved in energy metabolism. Two of them are involved in the respiratory chain: Cor1p (core protein of yeast coenzyme QH2-cytochrome c reductase) and Qcr7p which are two components of the cytochrome bc1 complex (complex III). These two proteins are essential for assembly and activity of the cytochrome bc1 complex and thus for respiratory growth. We identified multiple spots corresponding to two proteins that participate in ATP synthesis coupled proton transport (ATP syn- 
Table 3

MS identification of qualitative differences.

\begin{tabular}{|c|c|c|c|c|c|c|c|}
\hline Spot & Protein name & $\mathrm{AC}^{\mathrm{a}}$ & $\begin{array}{l}\text { Theoretical } \\
\mathrm{p} I / \mathrm{Mr}(\mathrm{kDa})\end{array}$ & $\begin{array}{l}\text { Experimental }^{\mathrm{c}} \\
\mathrm{p} I / \mathrm{Mr}(\mathrm{kDa})\end{array}$ & d & $\begin{array}{l}\text { No. of matched } \\
\text { peptides }\end{array}$ & $\begin{array}{l}\text { Sequence } \\
\text { coverage }{ }^{f}(\%)\end{array}$ \\
\hline \multicolumn{8}{|c|}{ Proteins detected exclusively in BY4741 strain } \\
\hline A & Peroxisomal-coenzyme A synthetase, FAT2 & P38137 & $9.9 / 60.49$ & $9.4 / 58.64$ & 110 & 16 & 50 \\
\hline B & Dihydroxyacid dehydratase, ILV3 & P39522 & $7.8 / 62.86$ & $6.6 / 34.86$ & 88 & 12 & 47 \\
\hline \multicolumn{8}{|c|}{ Proteins detected exclusively in BY4741 and in sco1- $\Delta$ mutant strain } \\
\hline C & Alpha-isopropylmalate synthase, LEU4 & P06208 & $5.9 / 68.41$ & $5.6 / 62.50$ & 113 & 18 & 42 \\
\hline D & Heat shock proteinSTI1 & P15705 & $5.4 / 66.26$ & $5.4 / 67.97$ & 137 & 26 & 56 \\
\hline \multicolumn{8}{|c|}{ Proteins detected exclusively in BY4741 and in sco2- $\Delta$ mutant strain } \\
\hline E & Protoporphyrinogen oxidase, HEM14 & P40012 & $10 / 59.70$ & $9.4 / 54.59$ & 145 & 27 & 47 \\
\hline $\mathrm{F}$ & Mitochondrial aldehyde dehydrogenase, ALD4 & P46367 & $6.7 / 56.72$ & $5.8 / 59.47$ & 90 & 20 & 38 \\
\hline G & $\begin{array}{l}\text { E1 alpha subunit of the pyruvate dehydrogenase (PDH) } \\
\text { complex, PDA1 }\end{array}$ & P16387 & $8.1 / 46.34$ & $6.2 / 47.82$ & 129 & 30 & 58 \\
\hline $\mathrm{H}$ & $\begin{array}{l}\text { Dihydrolipoamide acetyltransferase component (E2) of } \\
\text { pyruvate dehydrogenase (PDH) complex, LAT1 }\end{array}$ & P12695 & $7.9 / 51.82$ & $8.0 / 24.22$ & 85 & 12 & 29 \\
\hline \multicolumn{8}{|c|}{ Proteins detected exclusively in sco1- $\Delta$ mutant strain } \\
\hline I & D-lactate dehydrogenase, DLD1 & P32891 & $6.8 / 65.29$ & $5.7 / 62.01$ & 160 & 24 & 49 \\
\hline $\mathrm{J}$ & $\begin{array}{l}\text { Magnesium-activated aldehyde dehydrogenase, cytosolic, } \\
\text { ALD6 }\end{array}$ & P54115 & $5.2 / 54.41$ & $5.3 / 57.68$ & 92 & 13 & 37 \\
\hline \multicolumn{8}{|c|}{ Proteins detected exclusively in sco2- $\Delta$ mutant strain } \\
\hline K & Isocitrate dehydrogenase [NAD] subunit 1, IDH1 & P21954 & $9.5 / 48.19$ & $8.4 / 47.30$ & 108 & 21 & 46 \\
\hline $\mathrm{L}$ & ARS-binding factor 2, mitochondrial, ABF2 & Q02486 & $10 / 21.56$ & $9.8 / 18.62$ & 180 & 10 & 39 \\
\hline \multicolumn{8}{|c|}{ Proteins detected exclusively in sco1- $\Delta$ and in sco2- $\Delta$ mutant strain } \\
\hline M & Putative mitochondrial aconitase $2, \mathrm{ACO} 2$ & P39533 & $6.9 / 86.58$ & $6.1 / 26.97$ & 80 & 24 & 52 \\
\hline $\begin{array}{ll}\text { a } & \mathrm{Sv} \\
\text { b } & \mathrm{Pr} \\
\text { c } & \mathrm{M} \\
\mathrm{d}^{\mathrm{d}} & \mathrm{M} \\
\mathrm{e} & \mathrm{N} \\
{ }^{\mathrm{f}} & \mathrm{Pe}\end{array}$ & $\begin{array}{l}\text { ssProt/TrEMBL Accession number. } \\
\text { licted pI and Mr according to protein sequence. } \\
\text { sured pI and Mr values were experimentally determined w } \\
\text { SCOT score (Matrix Science, London, UK; http://www.matrix } \\
\text { nber of peptide masses matching the top hit from Ms-Fit PI } \\
\text { entage of amino acid sequence coverage of matched peptid }\end{array}$ & $\begin{array}{l}\text { mageMast } \\
\text { nce.com). }\end{array}$ & 2D Platinum & ing identified pro & Is with & lown parameters & a reference. \\
\hline
\end{tabular}

thase subunit alpha and ATP synthase subunit beta). Two of the 15 known proteins of the tricarboxylic acid cycle were down-regulated in the sco1- $\Delta$ mutant strain: Lsc1p that catalyzes the conversion of succinyl-CoA to succinate, and Mdh1p that catalyzes interconversion of malate and oxaloacetate. Among the identified proteins that are involved in C-compound and carbohydrate metabolism, we found Ach $1 \mathrm{p}$ and Gut2p required respectively for the utilization of acetate and glycerol as carbon sources. In addition to glycerol degradation, Gut2p is involved in the oxidation of cytoplasmic NADH in the mitochondria. It is part of a complex that includes the NADH dehydrogenase Nde1p (which is also downregulated in the sco1- $\Delta$ mutant) (Grauslund and Rønnow, 2000; Luttik et al., 1998; Metzler, 1977). Among the proteins downregulated in the sco1- $\Delta$ mutant we identified also one protein involved in protein biosynthesis and one in amino acids metabolism: the homo-isocitrate dehydrogenase Msd1p and Lys12p, required for the biosynthesis of lysine. Three proteins take part in protein folding and protein transport into the mitochondrial matrix: Ssc1p, Mge1p and Phb1p. Ssc1p belongs to the HSP70 family, involved in protein import into the mitochondrial matrix and is part of a complex pthat plays a role in protein translocation. Ssc1p interacts with Mge1p (a constituent of the mitochondrial import motor) (Truscott et al., 2003; Kozany et al., 2004; Horst et al., 1997; Kang et al., 1990). The lack of SCO1 causes the down-regulation of the protein Por1p (identified in multiple spots)also known as the voltage dependent anion-selective channel (YVDAC1) of the mitochondrial outer membrane, that is required for the maintenance of mitochondrial osmotic stability and mitochondrial membrane permeability. Por1p is involved in transport, of metabolites such as $\mathrm{NADH}$ through the mitochondrial outer membrane (Kmita et al., 2004; Lee et al., 1988). In regards to the oxygen and reactive oxygen species metabolism, the sco1- $\Delta$ mutant showed a decrease in the expression levels of Sod2p, which is the mitochondrial manganese-superoxide dismutase that is located in the mitochondrial matrix and protects cells against oxygen toxicity. Finally we found a down-regulated $0 m 45$, a mitochondrial outer membrane protein with unknown function. It has been suggested that $0 \mathrm{~m} 45 \mathrm{p}$ plays a role in the import of metabolic intermediates or proteins required for respiratory growth (Waizenegger et al., 2003).

Three proteins in the sco1- $\Delta$ mutant were found to be up-regulated in comparison to the wild type. Two of them, Ahp1p (alkyl hydroperoxide reductase) and Yhb1p (yeast hemoglobin-like protein) (identified in multiple spots), are involved in the response to oxidative stress. Ahp1p reduces hydroperoxides to protect cells against oxidative damage. Yhb1p is a flavohemoglobin involved in nitric oxide detoxification; it plays a role in oxidative stress and nitrosative stress responses. The other up-regulated protein is Cit1p, the citrate synthase that catalyzes the condensation of acetyl coenzyme A and oxaloacetate to form citrate; it is the rate-limiting enzyme of the TCA cycle (Kim et al., 1986; Jia et al., 1997). This enzyme is also up-regulated in the sco2- $\Delta$ mutant. In the sco2- $\Delta$ mutant strain we found that only two proteins were down-regulated in comparison to the wild type. The proteomic results confirm that only the lack of Sco1p causes the absence of a functional respiratory chain and consequently leads to mitochondrial dysfunction. In fact we found that the components of the respiratory chain, the ATP synthase complex, the TCA cycle and the proteins involved in metabolite and protein import across the mitochondrial membrane were down-regulated or not detectable, in comparison to the isogenic and the sco2- $\Delta$ mutant strains. In the sco1- $\Delta$ mutant there is also a decrease in the expression levels of enzymes involved in the metabolism of non-fermentable carbon sources such as glycerol (Gut2p) and ethanol (Ald4p). These data are also confirmed by the sco1- $\Delta$ mutant's reduced growth phenotype on non-fermentable carbon sources.

These proteomic findings imply that the sco1- $\Delta$ mutant makes no futile attempt to compensate for its respiratory-deficient state by up-regulating the expression of oxidative phosphorylation 
genes. On the contrary, it tries to respond by reconfiguring its metabolism. In fact, in these cells we found an increase in the expression levels of Cit $1 \mathrm{p}$, an enzyme of the TCA cycle which is usually up-regulated in the retrograde response. This is a pathway activated in cells with a compromised mitochondrial function that leads to the activation of genes that compensate for dysfunction (Liu and Butow, 1999). The main feature of this response is the activation of an alternative pathway for the production of TCA cycle intermediates (such as glutamate). One of these anaplerotic pathways is the glyoxylate cycle, which allows the cell to use acetate for the synthesis of carbohydrates and proteins. However, apart from Cit1p, we did not find any other protein involved in the retrograde response. This evidence suggests that the absence of Sco1p and consequently of a functional oxidative phosphorylation chain cause an irreversible damage to the mitochondria. After a weak attempt to overcome the absence of a functional respiratory chain, cells lose their damaged mitochondria. These data were also confirmed by the microscopic examination of cells with GFPlabelled mitochondria.

Two enzyme involved in the retrograde response are up-regulated in the sco2- $\Delta$ mutant (Cit1p and Idh1p). This indicates that the deletion of $\mathrm{SCO} 2$ causes a mitochondrial dysfunction too. Nevertheless the damage caused in this case is not so heavy and, in our study, it does not lead to noticeable phenotypic and proteomic differences in comparison to the control strain. Hence, the reported data suggest that $S \operatorname{co} 2 p$ in $S$. cerevisiae could have a role, although not fully understood, in mitochondrial respiration. The results presented in our study provide an interesting new insight concerning the relative roles of Sco1p and Sco2p in mitochondrial function. We found that both at the phenotypic and the proteomic level only absence of SCO1 has an effect on the mitochondrial function and stability. These differences may be attributable to a different biological function of the two proteins in the respiratory metabolism.

\section{Acknowledgements}

The authors thank K. Okamoto (University of Utah) and Hiroshi Kitagaki (National Research Institute of Brewing, Hiroshima) for providing the plasmid pYX142-mtGFP, ARS/CEN-LEU2. This work was supported by MIUR-PRIN 2003 and MIUR-PRIN 2005 grants and by NUGO FOOD-CT-2004-506360 grant.

We are grateful to Dr. Matteo Parri (University of Florence) for assistance in fluorescence microscopy.

\section{Appendix A. Supplementary material}

Supplementary data associated with this article can be found, in the online version, at doi:10.1016/j.mito.2009.01.002.

\section{References}

Bardel, J., Louwagie, M., Jaquinod, M., Jourdain, A., Luche, S., Rabilloud, T., Macherel, D., Garin, J., Bourguignon, J., 2002. A survey of the plant mitochondrial proteome in relation to development. Proteomics 2, 880-898.

Butow, R.A., Avadhani, N.G., 2004. Mitochondrial signaling, the retrograde response. Mol. Cell 14, 1-15.

Dickinson, E.K., Adams, D.L., Schon, E.A., Glerum, D.M., 2000. A human SCO2 mutation helps define the role of Sco1p in the cytochrome oxidase assembly pathway. J. Biol. Chem. 275, 26780-26785.

Fountoulakis, M., Berndt, P., Langen, H., Suter, L., 2002. The rat liver mitochondrial proteins. Electrophoresis 23, 311-328.

García-Rodríguez, L.J., Gay, A.C., Pon, L.A., 2007. Puf3p, a Pumilio family RNA binding protein, localizes to mitochondria and regulates mitochondrial biogenesis and motility in budding yeast. J. Cell. Biol. 176, 197-207.

Grauslund, M., Rønnow, B., 2000. Carbon source-dependent transcriptional regulation of the mitochondrial glycerol-3-phosphate dehydrogenase gene, GUT2, from Saccharomyces cerevisiae. Can. J. Microbiol. 46, 1096-1100.

Glerum, D.M., Shtanko, A., Tzagoloff, A., 1996. SCO1 and SCO2 act as high copy suppressors of a mitochondrial copper recruitment defect in Saccharomyces cerevisiae. J. Biol. Chem. 271, 20531-20535.
Hochstrasser, D.F., Patchornik, A., Merril, C.R., 1988. Development of polyacrylamide gels that improve the separation of proteins and their detection by silver staining. Anal. Biochem. 173, 412-423.

Horst, M., Oppliger, W., Rospert, S., Schönfeld, H.J., Schatz, G., Azem, A., 1997. Sequential action of two hsp70 complexes during protein import into mitochondria. EMBO J. 16, 1842-1849.

Jia, Y.K., Bécam, A.M., Herbert, C.J., 1997. The CIT3 gene of Saccharomyces cerevisiae encodes a second mitochondrial isoform of citrate synthase. Mol. Microbiol. 24, 53-59.

Jiang, J.C., Jaruga, E., Repnevskaya, M.V., Jazwinski, S.M., 2000. An intervention resembling caloric restriction prolongs life span and retards aging in yeast. FASEB J. 14, 2135-2137.

Kang, P.J., Ostermann, J., Shilling, J., Neupert, W., Craig, E.A., Pfanner, N., 1990 Requirement for hsp70 in the mitochondrial matrix for translocation and folding of precursor proteins. Nature 348, 137-143.

Kim, K.S., Rosenkrantz, M.S., Guarente, L., 1986. Saccharomyces cerevisiae contains two functional citrate synthase genes. Mol. Cell. Biol. 6, 1936-1942.

Kmita, H., Antos, N., Wojtkowska, M., Hryniewiecka, L., 2004. Processes underlying the upregulation of Tom proteins in $S$. cerevisiae mitochondria depleted of the VDAC channel. J. Bioenerg. Biomembr. 36, 187-193.

Kozany, C., Mokranjac, D., Sichting, M., Neupert, W., Hell, K., 2004. The J domainrelated cochaperone Tim16 is a constituent of the mitochondrial TIM23 preprotein translocase. Nat. Struct. Mol. Biol. 11, 234-241.

Lee, A.C., Xu, X., Blachy-Dyson, E., Forte, M., 1988. The role of yeast VDAC genes on the permeability of the mitochondrial outer membrane. J. Membr. Biol. 161, 173-181.

Lin, S.J., Kaeberlein, M., Andalis, A.A., Sturtz, L.A., Defossez, P.A., Culotta, V.C., Fink, G.R., Guarente, L., 2002. Calorie restriction extends Saccharomyces cerevisiae lifespan by increasing respiration. Nature 418, 344-348.

Liu, Z., Butow, R.A., 1999. A transcriptional switch in the expression of yeast tricarboxylic acid cycle genes in response to a reduction or loss of respiratory function. Mol. Cell. Biol. 19, 6720-6728.

Lode, A., Paret, C., Rödel, G., 2002. Molecular characterization of Saccharomyces cerevisiae Sco2p reveals a high degree of redundancy with Sco1p. Yeast 19, 909922.

Luttik, M.A., Overkamp, K.M., Kötter, P., de Vries, S., Van Dijken, J.P., Pronk, J.T., 1998 The Saccharomyces cerevisiae NDE1 and NDE2 genes encode separate mitochondrial NADH dehydrogenases catalyzing the oxidation of cytosolic NADH. J. Biol. Chem. 273, 24529-24534.

Magherini, F., Tani, C., Gamberi, T., Caselli, A., Bianchi, L., Bini, L., Modesti, A., 2007. Protein expression profiles in Saccharomyces cerevisiae during apoptosis induced by $\mathrm{H} 2 \mathrm{O} 2$. Proteomics 7, 1434-1445.

Meisinger, C., Sommer, T., Pfanner, N., 2000. Purification of Saccharomcyes cerevisiae mitochondria devoid of microsomal and cytosolic contaminations. Anal. Biochem. 287, 339-342.

Metzler, D.E., 1977. Biochemistry: The Chemical Reactions of Living Cells. Academic Press Inc., New York. pp. 100-104.

Millar, A.H., Sweetlove, L.J., Giegé, P., Leaver, C.J., 2001. Analysis of the Arabidopsis mitochondrial proteome. Plant Physiol. 127, 1711-1727.

Millard, P.J., Roth, B.L., Thi, H.P., Yue, S.T., Haugland, R.P., 1997. Development of the FUN-1 family of fluorescent probes for vacuole labeling and viability testing of yeasts. Appl. Environ. Microbiol. 63, 2897-2905.

Ohlmeier, S., Kastaniotis, A.J., Hiltunen, J.K., Bergmann, U., 2004. The yeast mitochondrial proteome, a study of fermentative and respiratory growth. J. Biol. Chem. 279, 3956-3979.

Palmer, J., 1993. Current issues in the chemistry of cytochrome c oxidase. Bioenerg. Biomembr. 25, 145-151.

Petrezselyova, S., Lalakova, J., Abelovska, L., Klobucnikova, V., Tomaska, L., 2008. A collection of yeast mutants selectively resistant to ionophores acting on mitochondrial inner membrane. Mitochondrion 8, 117-129.

Reungpatthanaphong, P., Dechsupa, S., Meesungnoen, J., Loetchutinat, C., Mankhetkorn, S., 2003. Rhodamine B as a mitochondrial probe for measurement and monitoring of mitochondrial membrane potential in drugsensitive and -resistant cells. J. Biochem. Biophys. Methods 57, 1-16.

Schulze, M., Rodel, G., 1989. Accumulation of the cytochrome c oxidase subunits I and II in yeast requires a mitochondrial membrane-associated protein, encoded by the nuclear SCO1 gene. Mol. Gen. Genet. 216, 37-43.

Smith Jr., D.L., McClure, J.M., Matecic, M., Smith, J.S., 2007. Calorie restriction extends the chronological lifespan of Saccharomyces cerevisiae independently of the Sirtuins. Aging Cell. 6, 649-662.

Truscott, K.N., Voos, W., Frazier, A.E., Lind, M., Li, Y., Geissler, A., Dudek, J., Müller, H., Sickmann, A., Meyer, H.E., Meisinger, C., Guiard, B., Rehling, P., Pfanner, N., 2003. A J-protein is an essential subunit of the presequence translocase-associated protein import motor of mitochondria. J. Cell. Biol. 63, 707-713.

Vilain, S., Cosette, P., Charlionet, R., Hubert, M., Lange, C., Junter, G.A., Jouenne, T., 2001. Substituting Coomassie brilliant blue for bromophenol blue in two dimensional electrophoresis buffers improves the resolution of focusing patterns. Electrophoresis 22, 4368-4374.

Visser, W., Van Spronsen, E.A., Nanninga, N., Pronk, J.T., Gijs Kuenen, J., Van Dijken, J.P., 1995. Effects of growth conditions on mitochondrial morphology in Saccharomyces cerevisiae. Anton. Leeuw. 67, 243-253.

Waizenegger, T., Stan, T., Neupert, W., Rapaport, D., 2003. Signal-anchor domains of proteins of the outer membrane of mitochondria: structural and functional characteristics. J. Biol. Chem. 278, 42064-42071.

Westermann, B., Neupert, W., 2000. Mitochondria-targeted green fluorescent proteins: convenient tools for the study of organelle biogenesis in Saccharomyces cerevisiae. Yeast 16, 1421-1427. 